Article

\title{
Application of Raman Spectroscopy for Characterizing Synthetic Non-Metallic Inclusions Consisting of Calcium Sulphide and Oxides
}

\author{
Francis Gyakwaa ${ }^{1, *}$, Matti Aula ${ }^{1}$, Tuomas Alatarvas ${ }^{1}{ }^{1}$, Tero Vuolio ${ }^{1}$, Qifeng Shu ${ }^{1}$, \\ Marko Huttula ${ }^{2}$ and Timo Fabritius ${ }^{1}$ \\ 1 Process Metallurgy Research Unit, University of Oulu, P.O. Box 4300, FI-90014 Oulu, Finland; \\ Matti.Aula@oulu.fi (M.A.); Tuomas.Alatarvas@oulu.fi (T.A.); Tero.Vuolio@oulu.fi (T.V.); \\ Qifeng.Shu@oulu.fi (Q.S.); timo.fabritius@oulu.fi (T.F.) \\ 2 Nano and Molecular Systems Research Unit (NANOMO), University of Oulu, P.O. Box 4300, \\ FI-90014 Oulu, Finland; Marko.Huttula@oulu.fi \\ * Correspondence: francis.gyakwaa@oulu.fi
}

Received: 25 February 2020; Accepted: 12 March 2020; Published: 20 March 2020

\begin{abstract}
The presence of non-metallic inclusions (NMI) such as sulphides and oxides may be detrimental to the control of the steel casting process and product quality. The need for their identification and characterization is, therefore, urgent. This study uses time-gated Raman spectroscopy for the characterization of synthetic duplex oxide-sulphide phases that contain $\mathrm{CaS}$ and the oxide phases of $\mathrm{Al}_{2} \mathrm{O}_{3}, \mathrm{CA}, \mathrm{C} 12 \mathrm{~A} 7, \mathrm{C} 3 \mathrm{~A}$, and $\mathrm{MgO} \cdot \mathrm{Al}_{2} \mathrm{O}_{3}$ (MA). Binary phase samples of CaS-MA, C3A-CaS, $\mathrm{C} 12 \mathrm{~A} 7-\mathrm{CaS}, \mathrm{Al}_{2} \mathrm{O}_{3}-\mathrm{CaS}$, and $\mathrm{MA}-\mathrm{CaS}$ were prepared with varying phase contents. The relative intensities of the Raman peaks were used to estimate the samples' phase content. For a quantitative estimation, linear regression calibration models were used to evaluate the change in phase content in the samples. The most suitable Raman peak ratios had mean absolute error (MAE) values ranging from 3 to $7 \mathrm{wt}$. \% for the external validation error, and coefficients of determination $\left(\mathrm{R}^{2}\right)$ values between 0.94 and 0.98 . This study demonstrated the use of Raman spectroscopy for the characterization of the calcium sulphide, magnesium aluminate spinel, $\mathrm{Al}_{2} \mathrm{O}_{3}$, and calcium aluminate phases of $\mathrm{CA}, \mathrm{C} 3 \mathrm{~A}$, and C12A7 in a duplex oxide-sulphide system, and it offers potential for inclusion characterization in steel.
\end{abstract}

Keywords: duplex oxide-sulphide; inclusions; Raman spectroscopy; characterization; steel

\section{Introduction}

The calcium treatment for aluminum-killed steels is commonly used to modify non-metallic inclusion (NMI) such as $\mathrm{Al}_{2} \mathrm{O}_{3}$ to less detrimental inclusions [1,2]. The main aim of the modification of inclusions is the control and transformation of the solid inclusions into fully or partially liquid inclusions by changing their chemical or phase composition. Calcium treatment of Al-killed steels can be used to obtain calcium aluminate inclusions with lower liquidus temperature compared to the steel melt. The use of calcium treatment to achieve more liquid inclusions has the potential to control castability challenges such as submerged entry nozzle (SEN) clogging $[3,4]$ at casting temperatures. The preferred inclusions are either low-melting calcium aluminate inclusions such as C12A7 or C3A and $C A$, which may be present in partial liquid inclusions $[5,6]$. However, the occurrence of solid CA2 and CA6 phases should be avoided [5].

Although calcium treatment plays a role in modifying high melting point inclusions, with low $\mathrm{Al}_{2} \mathrm{O}_{3}$ activity in the inclusions, elemental sulphur can react with calcium to form CaS inclusions. They are solid at casting temperatures and can be very detrimental to the steel quality $[7,8]$. For example, 
studies conducted by researchers [7-9] have demonstrated that CaS can be found in steel samples from billet [8] and hot-rolled plates [7]. Additionally, Abdelaziz et al. in 2009 [9] suggested that the formation of $\mathrm{CaS}$ may be largely associated with the addition of $\mathrm{Ca}$ to liquid steel.

The amount of calcium aluminate phases, such as C12A7, CA, C3A, and calcium sulphides, generally depends on the calcium and sulphur contents, the activity of the aluminum, and the temperature of the molten steel [6]. Therefore, the study of calcium aluminate and sulphide inclusions has received much attention, with various characterization techniques, such as SEM-EDS (scanning electron microscopy-energy dispersive X-ray spectroscopy $[7,8]$, confocal scanning laser microscopy (CSLM) [10], and others [3], used to understand the transformation and control measures for inclusions. Using Raman spectroscopy presents a potential characterization technique for inclusion studies. The utilization of Raman spectroscopy as a characterization technique may perform better than conventional methods when comparing the duration for sample preparation and the acquisition of measurement results.

Additionally, phases such as $\mathrm{Al}_{2} \mathrm{O}_{3}, \mathrm{MgO} \cdot \mathrm{Al}_{2} \mathrm{O}_{3}, \mathrm{C} 12 \mathrm{~A} 7, \mathrm{CA}, \mathrm{C} 3 \mathrm{~A}$, and $\mathrm{CaS}$ have been measured and demonstrated to be Raman active [11-15]. Furthermore, Raman spectroscopy is found to be applicable in various research fields for quantitative and qualitative analysis [16], including some studies already done on synthetic $[17,18]$ and actual [19] inclusion phase studies. However, spectroscopic techniques like Raman spectroscopy have not been used in detail to study duplex oxide-sulphide inclusions like C12A7-CaS, C3A-CaS, and CA-CaS. These duplex oxide-sulphides have been demonstrated by researchers [20-22] to be present in some steel samples. Other inclusions could also be possible, for example, $\mathrm{Al}_{2} \mathrm{O}_{3}-\mathrm{CaS}$ and $\mathrm{MgAl}_{2} \mathrm{O}_{4}-\mathrm{CaS}$, which could be the intermediate product during calcium treatment $[23,24]$.

The authors' previous studies focused on the use of Raman spectroscopy for characterizing calcium-aluminate $\left(\mathrm{CaO}-\mathrm{Al}_{2} \mathrm{O}_{3}\right)$ inclusions [17] and calcium aluminate-spinel $\left(\mathrm{MgAl}_{2} \mathrm{O}_{4}\right)$ [18] in a binary system. However, these studies were limited to only oxides, and the application of Raman spectroscopy for characterizing potential detrimental sulphide inclusions such as CaS associated with oxides were not studied. Furthermore, the literature [25] has suggested that free CaS is rarely observed compared with $\mathrm{CaS}$ associated with modified calcium aluminate inclusions that may be partly liquid by characterizing steel samples from plant trials with varying calcium additions. The above studies [20-25] show the need to characterize duplex oxide-sulphide inclusions.

This study examined the applicability of Raman spectroscopy to characterize synthetic duplex oxide-sulphide inclusions consisting of calcium aluminate, the sulphide binary phases of CA-CaS, $\mathrm{C} 12 \mathrm{~A} 7-\mathrm{CaS}$, and C3A-CaS. Additionally, characterization of $\mathrm{Al}_{2} \mathrm{O}_{3}-\mathrm{CaS}$ and $\mathrm{MgO} \cdot \mathrm{Al}_{2} \mathrm{O}_{3}-\mathrm{CaS}$ samples was studied.

\section{Materials and Methods}

\subsection{Material}

The chemicals used for this study were aluminum oxide $\left(\mathrm{Al}_{2} \mathrm{O}_{3}\right)$, calcium oxide $(\mathrm{CaO})$, monocalcium aluminate $\mathrm{CaO} \cdot \mathrm{Al}_{2} \mathrm{O}_{3}(\mathrm{CA})$, calcium sulphide (CaS), and aluminate spinel, $\mathrm{MgO} \cdot \mathrm{Al}_{2} \mathrm{O}_{3}$ (MA). The chemical powders had a purity that ranged from $99.7 \%$ to $99.9 \%$ and were all obtained from Alfa Aesar.

\subsection{Methods}

Sample Preparation

$\mathrm{C} 3 \mathrm{~A}$ and $\mathrm{C} 12 \mathrm{~A} 7$ phases were prepared from aluminum oxide $\left(\mathrm{Al}_{2} \mathrm{O}_{3}\right)$ and calcium oxide $(\mathrm{CaO})$ powders, based on the $\mathrm{CaO} / \mathrm{Al}_{2} \mathrm{O}_{3}$ ratios within a $\mathrm{CaO}-\mathrm{Al}_{2} \mathrm{O}_{3}$ binary system. Sample pellets were prepared and sintered in a chamber furnace at a temperature of $1350^{\circ} \mathrm{C}$, and the process was repeated to achieve $\mathrm{C} 3 \mathrm{~A}$ and $\mathrm{C} 12 \mathrm{~A} 7$ phase samples. 
The required proportions of the phases $\left(\mathrm{C} 12 \mathrm{~A} 7, \mathrm{CA}, \mathrm{C} 3 \mathrm{~A}, \mathrm{Al}_{2} \mathrm{O}_{3}, \mathrm{CaS}\right.$, and $\left.\mathrm{MgO} \cdot \mathrm{Al}_{2} \mathrm{O}_{3}\right)$ were used to prepare the synthetic binary phase samples. Thorough mixing was carried out to ensure that the binary phase samples were homogenous. Sintering at a higher temperature is unsuitable for preparing the synthetic phase samples because $\mathrm{CaS}$ is very sensitive to heat. Careful mixing was therefore carried out several times to achieve homogenous samples. The homogeneity of the prepared binary samples was verified using both X-ray diffraction (XRD) and X-ray fluorescence (XRF) analysis by measuring replicates of the same sample.

\subsection{Analytical Techniques}

XRD and XRF were both used to verify the prepared samples to estimate the phase weight percentage and for elemental composition analysis.

\subsubsection{X-ray Diffraction (XRD)}

The XRD instrument used for the sample phase identification in this study was the Rigaku SmartLab $9 \mathrm{KW}$ model. The instrument setup included a Cu source lamp with $45 \mathrm{kV}$ and $200 \mathrm{~mA}$ settings ( $9 \mathrm{~kW}$ rotating anode) and Bragg-Brentano para-focusing geometry ( $300 \mathrm{~mm}$ goniometer) and had an acquisition speed of 3 degrees per min with 0.02 degrees per step. Other features were 5 -degree Soller slits used on both sources and a 10-mm limiting slit located at the source side of the samples in standard glass holders and on the analyser side.

\subsubsection{X-ray Fluorescence (XRF)}

The University of Oulu's Centre for Material Analysis provided XRF to conduct an elemental analysis on the prepared samples to estimate the elemental composition. The XRF instrument used for this study is Panalytical, with a maximum power of $4 \mathrm{~kW}$, Axios Max model, with a setup consisting of an $\mathrm{X}$-ray generator $\mathrm{Rh}$ tube. SuperQ was the analysis software used for elemental analysis.

\subsubsection{Raman Spectroscopy}

Raman spectroscopy is a vibrational spectroscopic analytical technique that operates on a principle based on an inelastic scattering of monochromatic light which creates a change in energy to study the vibrational and rotational modes of the excited molecules of a sample [26,27]. This change in energy in a sample during Raman spectroscopy measurement is considered a characteristic of the vibrational modes of the molecule in the material. The Raman spectrum thus acquired from a sample is regarded as the fingerprint of the individual component present in the sample.

The Raman spectrum obtained from a sample has some features, such as peak intensity, peak or shift (band) position, and full width at half maximum (FWHM), which provide information concerning the components in the material measured with Raman spectroscopy. For example, the Raman shift (band) position illustrates the material's phase or stoichiometric content, while the peak intensity $(I)$ or area shows the sample's phase component concentration. The use of Raman spectroscopy as a characterization technique has also gained application in various fields, such as medicine, steelmaking for slag studies [16], and other research sectors.

A TimeGated ${ }^{\circledR}$ Raman spectrometer (TG532 M1) supplied by TimeGated Instruments Ltd., Oulu, Finland was used in this study. Some of the device's features include a spectrometer equipped with a pulsed laser of $532 \mathrm{~nm}$, with a pulse width of 150 picosecond (ps) and a fiber-coupled frequency range from 40 to $100 \mathrm{kHz}$. The instrument setup also had a probe head made of $200 \mu \mathrm{m}$ collection fibre with a spot size of $1 \mathrm{~mm}$, a laser with a spectral width of less than $0.1 \mathrm{~nm}$, a complementary metal oxide semiconductor (CMOS) single-photon avalanche diode (SPAD) CMOS-SPAD array detector, a Photonics RPB532 w/105 $\mu \mathrm{m}$ excitation fibre, a fibre-coupled spectrograph, and delay electronics.

The Raman spectroscopy measurements were made at ambient conditions with a wavenumbers range of 100-1100 $\mathrm{cm}^{-1}$, a spectra acquisition time of 1-3 min, and a resolution of $10 \mathrm{~cm}^{-1}$. Each sample was measured five times with the Raman spectroscopy, with mixing done (for homogeneity) on the 
same after each measurement. A rotating sample holder stage to obtain an average spectrum for each batch of the measured sample was used. These steps were considered to ensure good repeatability and to reduce the effect of sample inhomogeneity. The Raman data used for this study was obtained from the averaged signal of five measurements per sample. The Raman spectra obtained from each sample were relatively stable; therefore, the variability of the Raman signal in the Raman data within each sample measured was found insignificant. The pre-processing software package provided by TimeGated Instrument treated the signal with the background subtraction. The time-gated Raman spectroscopy (TimeGated ${ }^{\circledR}$ ) used for this study was designed for effective fluorescence suppression compared to conventional Raman spectroscopy.

\subsection{Calibration Model}

The study used a calibration model to establish a relationship between different Raman peak ratios and the samples' phase content. The calibration model was used to examine variance in the phase content in a sample by using the total Raman spectrum to describe the relative intensities of the peaks present in the Raman spectrum. A calibration feature candidate for this study is expressed as:

$$
x_{c}=\frac{I_{k}}{\left(I_{n}+I_{k}\right)}
$$

where $I_{k}$ is the intensity for the Raman shift $k, x_{c}$ is the calibration feature candidate, and In represents the intensity corresponding to the Raman shift $n$. The use of relative intensities treats the signal similarly as does the unit normalization, and thus additional normalization was not carried out. The average mean absolute error (MAE) was calculated using $4 \mathrm{~N}$ repetitions for the cross-validation and a detailed description of how the calibration model identification and the selection process were conducted can be found in [18].

\section{Results and Discussion}

\subsection{Reference Data}

Figures 1 and 2 illustrate some examples of XRD spectra for binary samples of MA-CaS and CaS- $-\mathrm{Al}_{2} \mathrm{O}_{3}$, prepared for phase identification and measured with an XRD instrument. Figure 1 represents XRD spectra for selected samples for CaS-MA, where (i), (ii), and (iii) correspond to the $20 \%, 60 \%$, and $80 \%$ phase fractions of $\mathrm{CaS}$ in the sample. Similarly, Figure 2 also shows $\mathrm{Al}_{2} \mathrm{O}_{3}-\mathrm{CaS}$, where $(a),(b)$, and (c) correspond to the $20 \%, 60 \%$, and $80 \%$ phase fractions of $\mathrm{CaS}$ in the sample. To further examine and verify the samples' component, XRF measurements were made for elemental compositional analysis.

These two analytical techniques were considered in this study as complementary methods, where $\mathrm{XRD}$ provided information concerning individual phase weight percentage in the sample, and XRF for estimating the elemental composition of the prepared samples [28]. Tables 1 and 2 illustrate some examples of binary samples (MA-CaS and $\mathrm{CaS}-\mathrm{Al}_{2} \mathrm{O}_{3}$ ) used to establish a relationship between the initial sample composition and composition by XRD and XRF analysis. The XRD and XRF data were obtained from the samples where the phases estimated based on elemental analysis from XRF were compared with the phase weight percentages for the samples' XRD composition. Table 1 shows the values for the initial sample composition, XRD, and XRF analysis for MA-CaS, and Table 2 represents a binary sample for $\mathrm{Al}_{2} \mathrm{O}_{3}-\mathrm{CaS}$, which served as a comparison for initial sample composition and XRD and XRF results. 


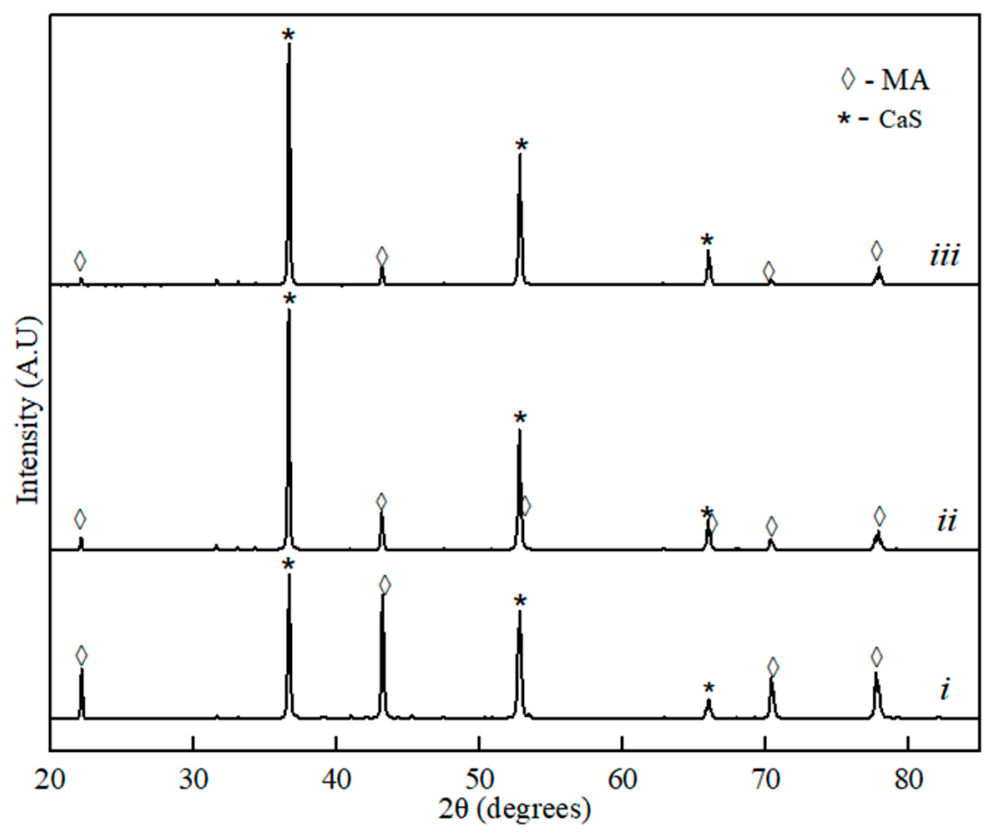

Figure 1. XRD spectra for the binary sample of $\mathrm{MgO} \cdot \mathrm{Al}_{2} \mathrm{O}_{3}$ (MA)-CaS: (i) $20 \%$ of $\mathrm{CaS}$, (ii) $60 \%$ of $\mathrm{CaS}$, and (iii) $80 \%$ of the CaS phase component.

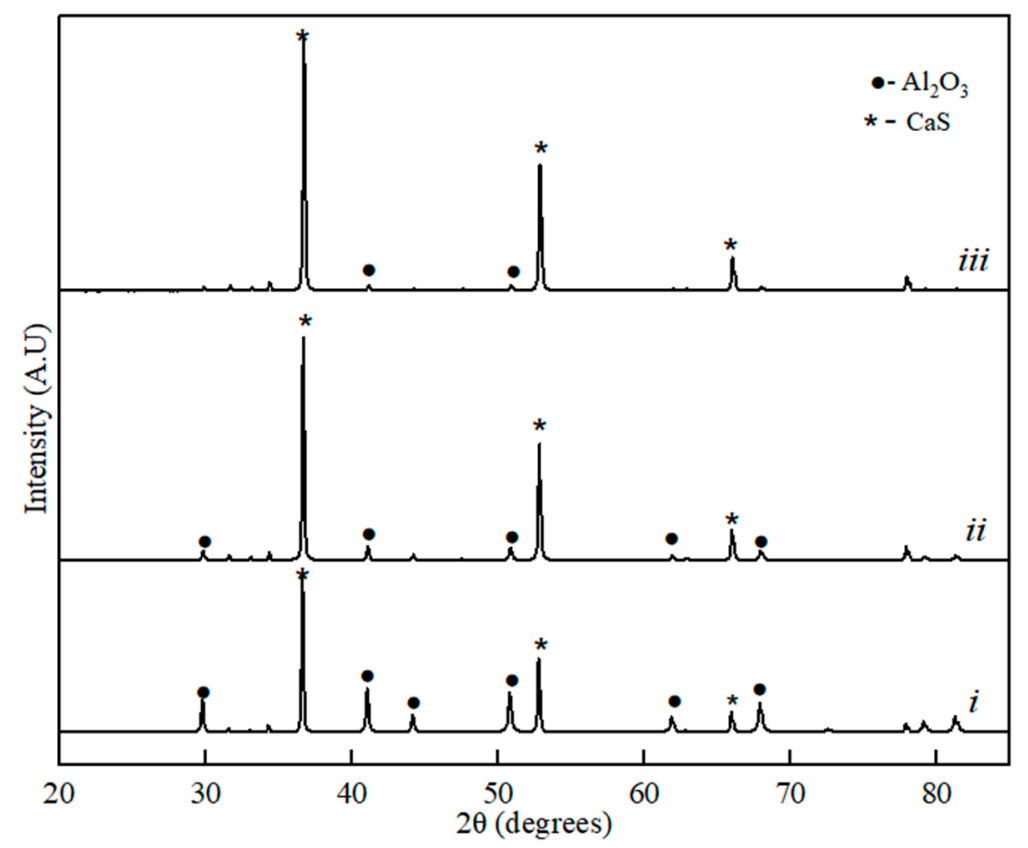

Figure 2. XRD spectra for the binary sample of $\mathrm{CaS}-\mathrm{Al}_{2} \mathrm{O}_{3}$ : (i) $20 \%$ of $\mathrm{CaS}$, (ii) $60 \%$ of $\mathrm{CaS}$, and (iii) $80 \%$ of the CaS phase component.

Table 1. Initial sample composition, $\mathrm{XRD}$ and $\mathrm{XRF}$ analyses for binary calcium sulphide-aluminate spinel phases of $\mathrm{MgO} \cdot \mathrm{Al}_{2} \mathrm{O} 3(\mathrm{MA})-\mathrm{CaS}$.

\begin{tabular}{cccccccccc}
\hline \multicolumn{2}{c}{$\begin{array}{c}\text { Initial Phase } \\
\text { Composition } \\
(\mathbf{w t} \%)\end{array}$} & \multicolumn{2}{c}{$\begin{array}{c}\text { XRD Phase } \\
\text { Composition } \mathbf{( w t} \%)\end{array}$} & \multicolumn{2}{c}{ XRF Calculated Phase Composition (wt\%) and Elemental Data } \\
\hline $\mathrm{MgO} \cdot \mathrm{Al}_{2} \mathrm{O}_{3}$ & $\mathrm{CaS}$ & $\mathrm{MgO} \cdot \mathrm{Al}_{2} \mathrm{O}_{3}$ & $\mathrm{CaS}$ & $\mathrm{MgO} \cdot \mathrm{Al}_{2} \mathrm{O}_{3}$ & $\mathrm{CaS}$ & $\mathrm{Ca}$ & $\mathrm{S}$ & $\mathrm{Al}$ & $\mathrm{Mg}$ \\
90 & 10 & 91 & 9 & 87 & 13 & 7.27 & 7.03 & 33.27 & 12.68 \\
80 & 20 & 84 & 16 & 76 & 24 & 13.29 & 12.63 & 27.77 & 11.22 \\
30 & 70 & 34 & 66 & 31 & 69 & 43.78 & 35.02 & 7.97 & 3.70 \\
20 & 80 & 25 & 75 & 21 & 79 & 38.48 & 30.86 & 11.63 & 5.17 \\
10 & 90 & 12 & 88 & 7 & 93 & 51.94 & 41.55 & 2.31 & 1.30 \\
\hline
\end{tabular}


Table 2. Initial sample composition, XRD and XRF analyses for binary aluminum oxide-calcium sulphide phases of Al2O3-CaS.

\begin{tabular}{ccccccccc}
\hline $\begin{array}{c}\text { Initial Phase } \\
\text { Composition } \mathbf{( w t} \%)\end{array}$ & \multicolumn{2}{c}{$\begin{array}{c}\text { XRD Phase } \\
\text { Composition } \mathbf{( w t} \%)\end{array}$} & \multicolumn{3}{c}{ XRF Calculated Phase Composition (wt\%) and Elemental Data } \\
\hline $\mathrm{Al}_{2} \mathrm{O}_{3}$ & $\mathrm{CaS}$ & $\mathrm{Al}_{2} \mathrm{O}_{3}$ & $\mathrm{CaS}$ & $\mathrm{Al}_{2} \mathrm{O}_{3}$ & $\mathrm{CaS}$ & $\mathrm{Ca}$ & $\mathrm{S}$ & $\mathrm{Al}$ \\
10 & 90 & 8 & 92 & 15 & 85 & 46.81 & 37.44 & 8.16 \\
20 & 80 & 18 & 82 & 24 & 76 & 42.08 & 33.66 & 12.66 \\
30 & 70 & 28 & 72 & 34 & 66 & 36.26 & 29.01 & 18.23 \\
60 & 40 & 58 & 42 & 57 & 43 & 23.55 & 18.83 & 30.41 \\
70 & 30 & 72 & 28 & 69 & 31 & 17.28 & 13.82 & 36.38 \\
90 & 10 & 91 & 9 & 89 & 11 & 6.28 & 5.02 & 46.95 \\
\hline
\end{tabular}

\subsection{Analysis of Phase Content Based on Raman Spectra}

The main Raman band (shift) identified from the Raman spectroscopy measurements for each specified phase used to prepare the samples was compared with previous studies [11-15]. Table 3 shows the Raman shift or band $\left(\mathrm{cm}^{-1}\right)$ for measured samples in this work and the published reference materials. Figure 3 illustrates the Raman spectra for the initial phases used to prepare the binary samples.

Table 3. Reference and measured Raman shift $\left(\mathrm{cm}^{-1}\right)$ for starting phases of CA, CaS, C12A7, C3A, $\mathrm{Al}_{2} \mathrm{O}_{3}$, and $\mathrm{MgO} \cdot \mathrm{Al}_{2} \mathrm{O}_{3}$ (where $\mathrm{s}$ is strong, $\mathrm{m}$ is medium, and $\mathrm{w}$ is weak).

\begin{tabular}{cccc}
\hline Phase & Measured Peaks [Raman Shift, $\mathbf{c m}^{-\mathbf{1}}$ ] & Reference [Raman Shift, $\mathbf{c m}^{-\mathbf{1}}$ ] & Reference \\
\hline $\mathrm{CaS}$ & $156-160 \mathrm{~s}, 190-200 \mathrm{~m}, 478 w$ & $160 \mathrm{~s}, 185 \mathrm{~m}, 215( \pm 15), 485( \pm 10) \mathrm{w}$ & {$[12]$} \\
$\mathrm{C} 12 \mathrm{~A} 7$ & $517 \mathrm{~s}, 781 \mathrm{~m}, 314 \mathrm{~m}$ & $312-333 \mathrm{~m}, 516-517 \mathrm{~m}, 772 \mathrm{~m}, 779 \mathrm{~m}$ & {$[13,15]$} \\
$\mathrm{C} 3 \mathrm{~A}$ & $766 \mathrm{~s}, 512 \mathrm{~m}$ & $756-760 \mathrm{~s}, 506-508 \mathrm{~m}$ & {$[13,15]$} \\
$\mathrm{Al}_{2} \mathrm{O}_{3}$ & $420 \mathrm{~s}, 386 \mathrm{~m}, 760 \mathrm{~m}$ & $413-420 \mathrm{~s}, 375-382 \mathrm{~m}, 748-751 \mathrm{~m}$ & {$[11]$} \\
$\mathrm{MgO} \cdot \mathrm{Al}_{2} \mathrm{O}_{3}$ & $412 \mathrm{~s}, 674 \mathrm{~m}, 773 \mathrm{~m}$ & $409-412 \mathrm{~s}, 767-772 \mathrm{~m}, 666-674 \mathrm{~m}$ & {$[14]$} \\
\hline
\end{tabular}

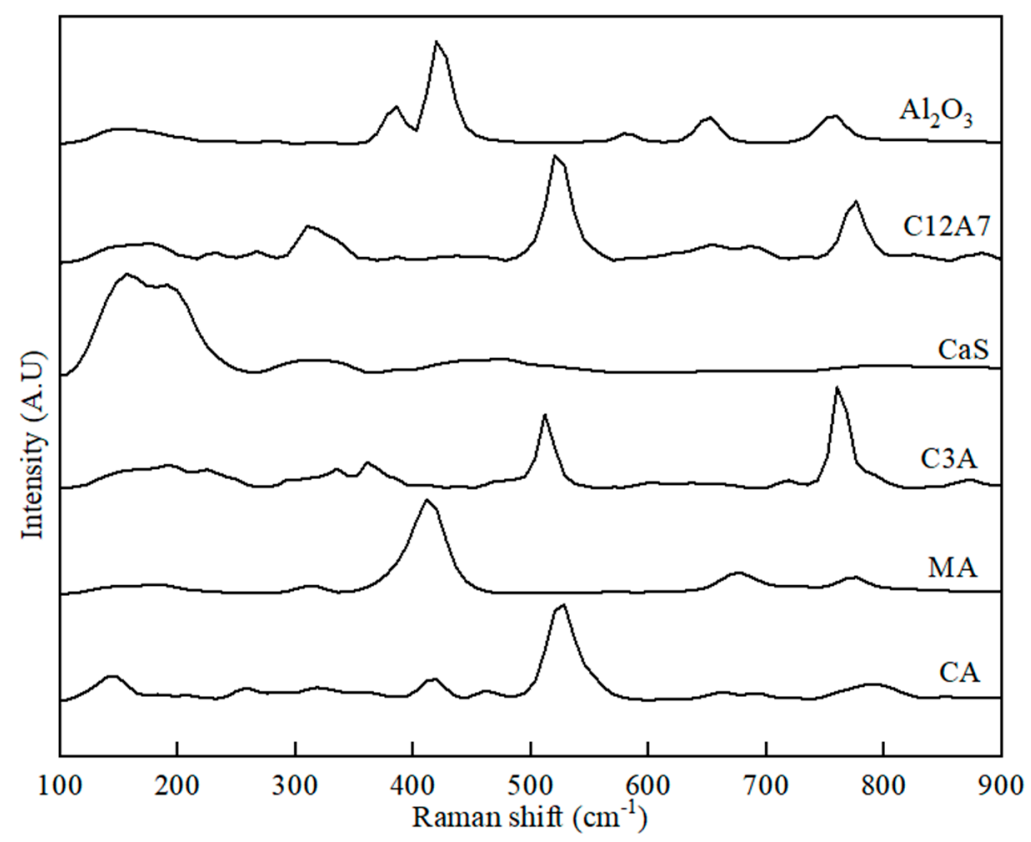

Figure 3. Raman spectra for initial phases of $\mathrm{Al}_{2} \mathrm{O}_{3}, \mathrm{C} 12 \mathrm{~A} 7, \mathrm{CaS}, \mathrm{C} 3 \mathrm{~A}, \mathrm{MA}$, and CA used for preparing the binary phase samples.

The observations made for the samples measured with Raman spectroscopy show that a change in phase content in the binary samples system may have a corresponding effect on the relative intensity of the peaks. They are presented in Figures 4-8. Section 2.3.3 briefly describes the information that can be obtained from the intensity of a Raman peak for Raman spectroscopy measurements. Figures 4-8 are, 
therefore, used to qualitatively explain how the relative intensity of the peaks associated with a specific phase can be used to estimate the particular phase content present in the samples.

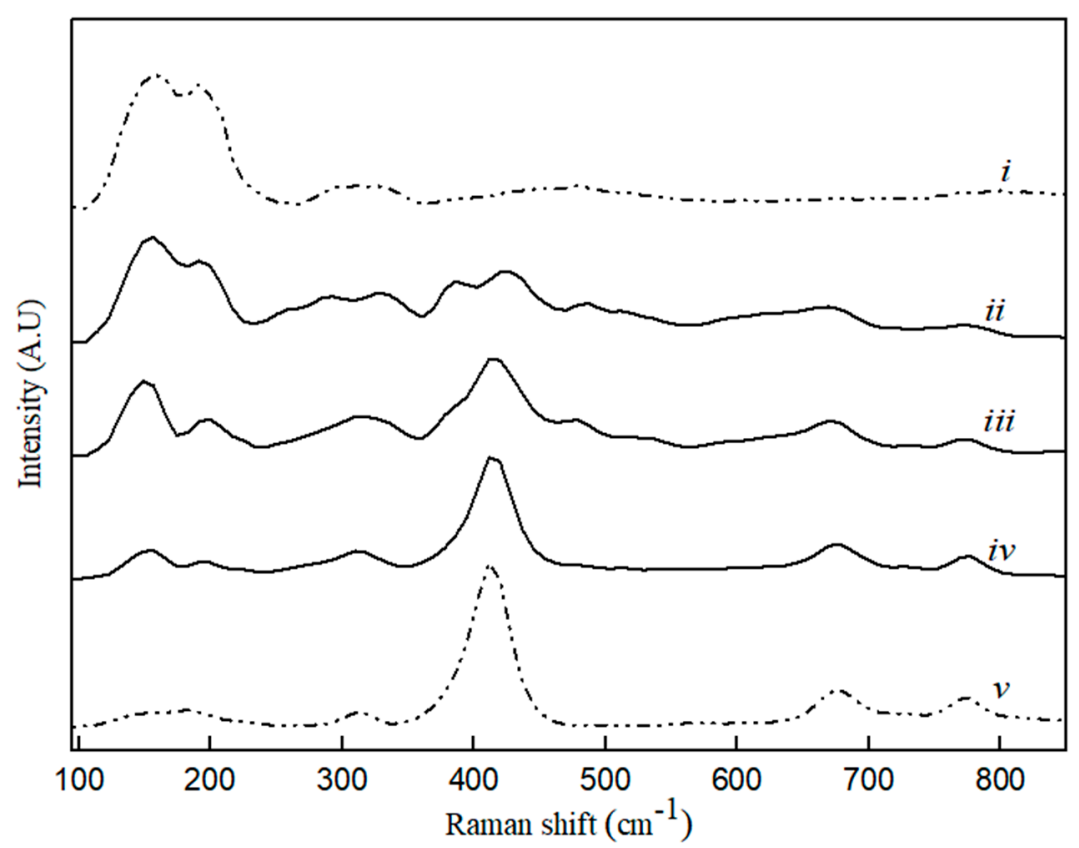

Figure 4. Raman spectra for CaS (i), MA (v) and binary MA-CaS phase sample with CaS content, where (ii) 80 wt. \%, (iii) 60 wt. \%, and (iv) 20 wt. \%.

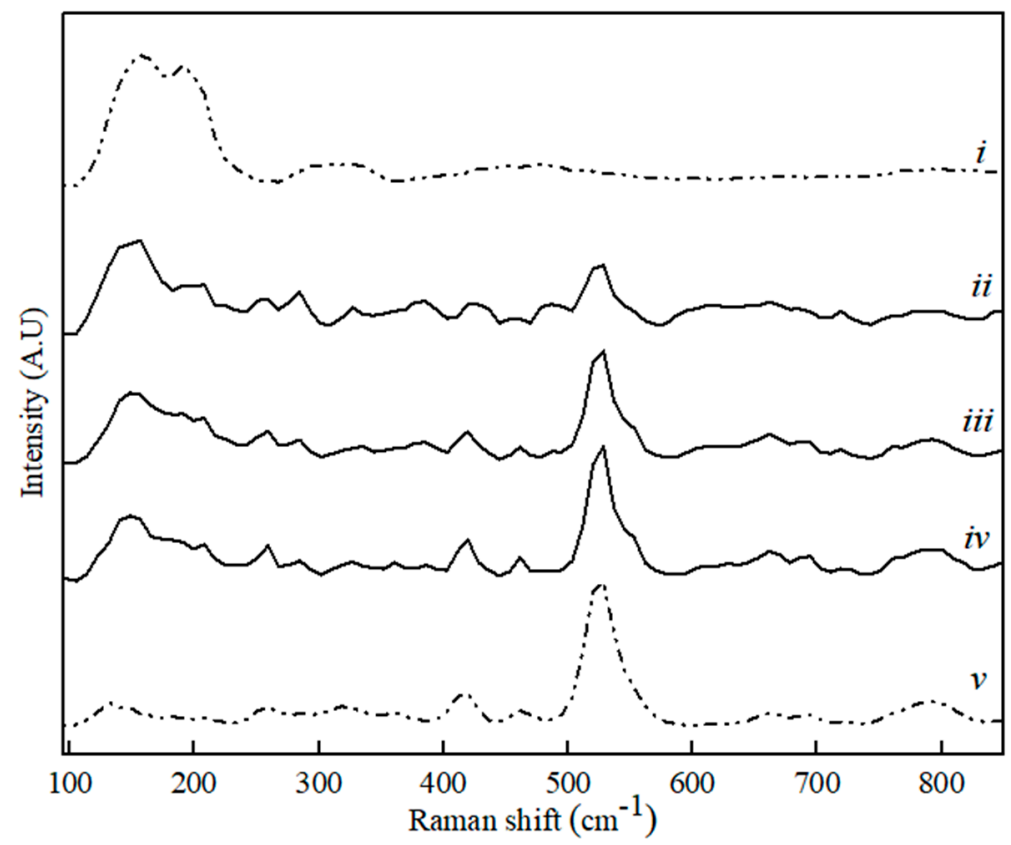

Figure 5. Raman spectra for CaS $(i), \mathrm{CA}(v)$ and binary CA-CaS phase sample with CaS content, where (ii) 80 wt. \%, (iii) $60 \mathrm{wt}$ \%, and (iv) 20 wt. \%. 


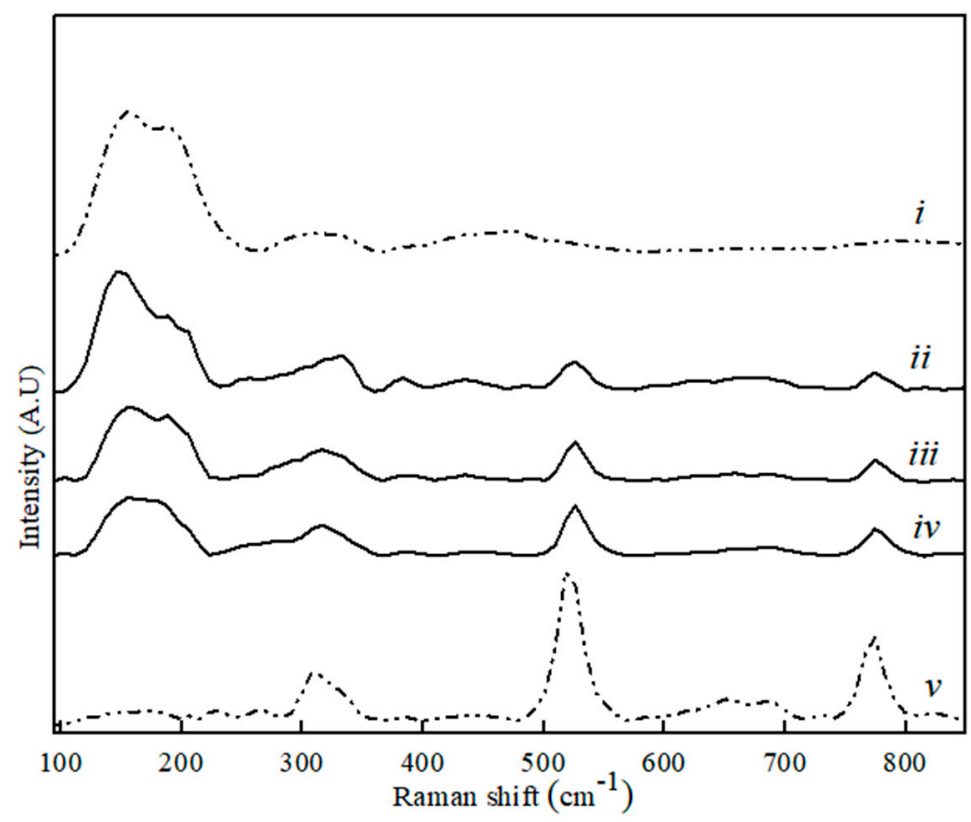

Figure 6. Raman spectra for CaS (i), C12A7 (v) and binary CaS-C12A7 phase sample with CaS content, where (ii) 80 wt. \%, (iii) 60 wt. \%, and (iv) 20 wt. \%.

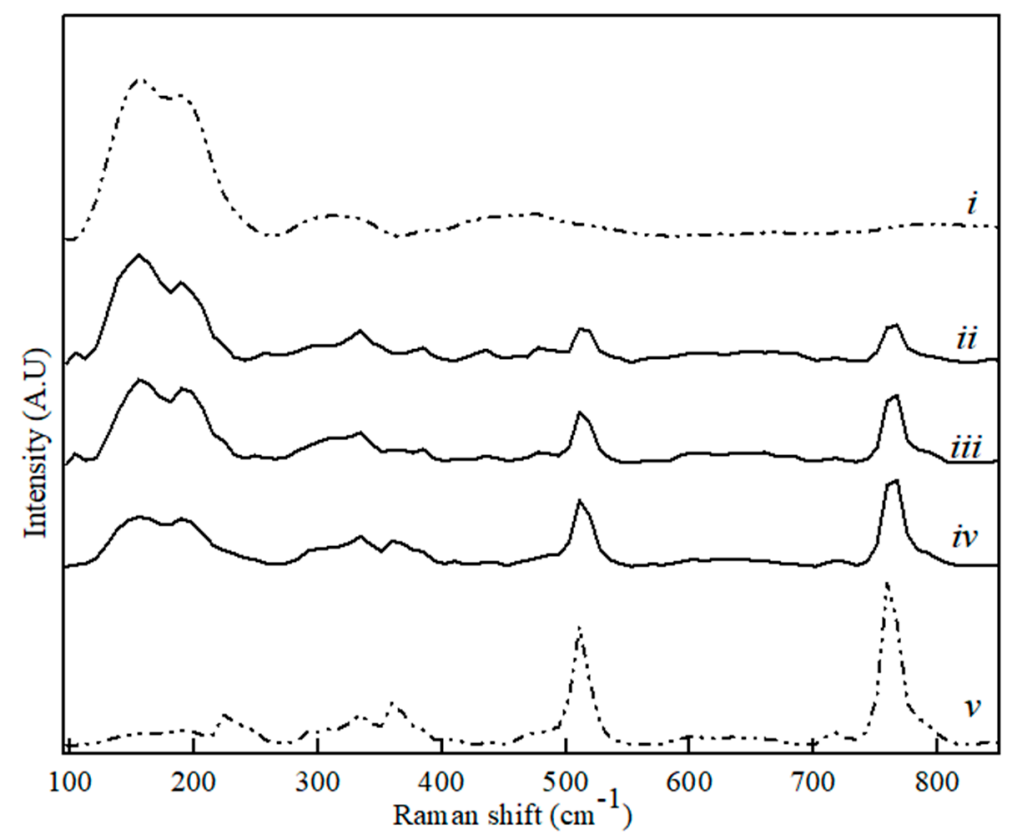

Figure 7. Raman spectra for CaS (i), C3A (v) and binary CaS-C3A phase sample with CaS content, where (ii) 80 wt. \%, (iii) 60 wt. \%, and (iv) 20 wt. \%. 


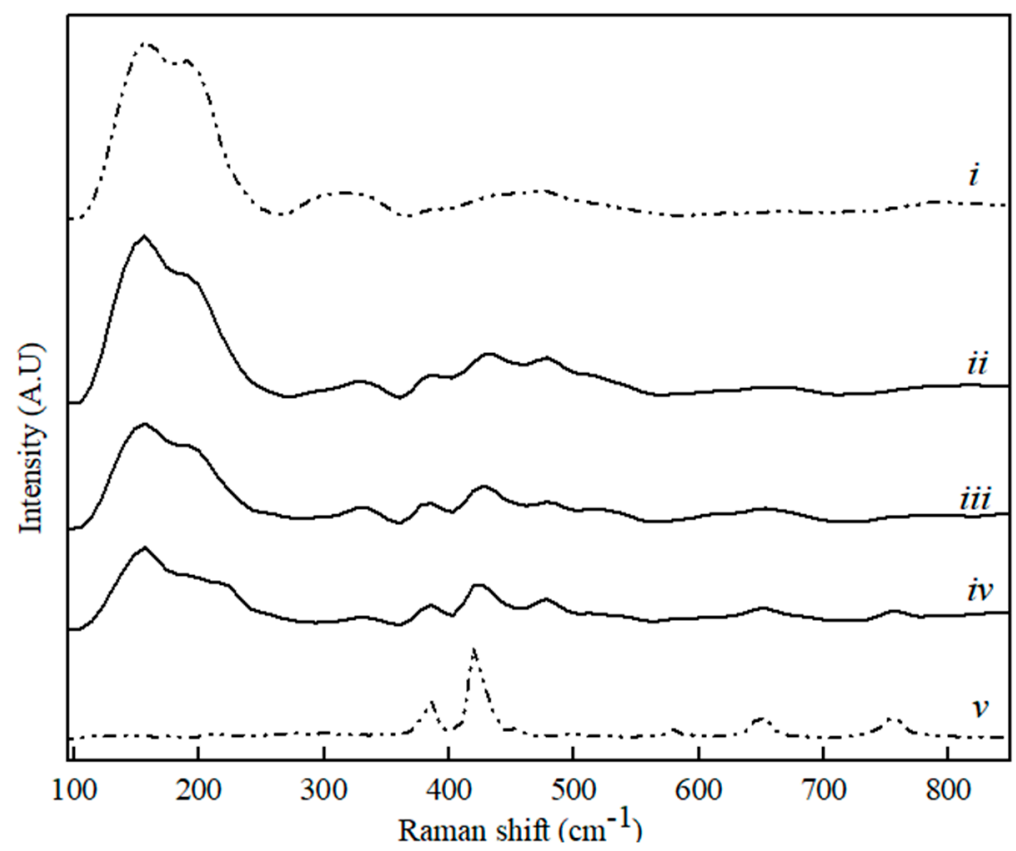

Figure 8. Raman spectra for $\mathrm{CaS}(i), \mathrm{Al}_{2} \mathrm{O}_{3}(v)$ and binary $\mathrm{CaS}-\mathrm{Al}_{2} \mathrm{O}_{3}$ phase sample with CaS content, where (ii) $80 \mathrm{wt}$ \%, (iii) 60 wt. \%, and (iv) $20 \mathrm{wt.} \%$.

\subsection{1. $\mathrm{CA}-\mathrm{CaS}$ and $\mathrm{MgO} \cdot \mathrm{Al}_{2} \mathrm{O}_{3}(\mathrm{MA})-\mathrm{CaS}$ Samples}

The Raman spectra shown in Figure 4 are for samples containing $\mathrm{CaS}$ and magnesium aluminate (MA) spinel, and are used to explain how a change in a sample's phase content can affect the relative Raman intensity. Figure 4 shows that an increment in the CaS phase fraction in the MA-CaS samples showed a corresponding rise in the Raman shift (band) within a region of $157-162 \mathrm{~cm}^{-1}$. This increase in intensity within this Raman shift region relates to when the phase content for $\mathrm{CaS}$ increased, because the most intense peak for this phase was around $157 \mathrm{~cm}^{-1}$. Additionally, for the MA-CaS samples, an increase in the MA phase content showed a corresponding increase in the Raman shift in the region of $410-420 \mathrm{~cm}^{-1}$ and can be attributed to this phase, because the most intense Raman shift located at $412 \mathrm{~cm}^{-1}$ was a Raman peak feature associated with the MA phase.

Figure 5 presents the Raman spectra obtained from the binary samples consisting of $\mathrm{CA}$ and $\mathrm{CaS}$, where it can be observed that an increase in the CA phase fraction had Raman spectra, illustrating an increase in peak intensity in the region of $520-524 \mathrm{~cm}^{-1}$. CA's most intense Raman shift (band) was observed at approximately $524 \mathrm{~cm}^{-1}$, and the Raman peak within the range of $520-524 \mathrm{~cm}^{-1}$ only increased with a corresponding increase in the phase fraction of CA in the CA-CaS samples. Furthermore, an increase in the $C A$ phase content illustrated a characteristic feature, with the appearance of a peak shoulder in the $545-549 \mathrm{~cm}^{-1}$ region. Varying the phase content in the CA-CaS samples provided a similar observation to the one made in Figure 4, where an increment in the phase fraction of CaS demonstrated a rising peak intensity in the Raman shift in the region of $157-162 \mathrm{~cm}^{-1}$.

\subsubsection{C12A7-CaS and C3A-CaS Samples}

Figures 6 and 7 show the Raman spectra for binary samples for the calcium aluminate phases of C12A7, C3A, and calcium sulphide (CaS). Figure 6 presents the samples that contain CaS and C12A7, showing that when the phase fraction of $\mathrm{C} 12 \mathrm{~A} 7$ in the sample increased, a corresponding increase in the Raman shift in the region of $517-520 \mathrm{~cm}^{-1}$ was observed. This rise in intensity may be associated with the increasing phase fraction of $\mathrm{C} 12 \mathrm{~A} 7$, because the most intense Raman peak for this phase was located around $517 \mathrm{~cm}^{-1}$.

For the samples comprising $\mathrm{C} 3 \mathrm{~A}$ and $\mathrm{CaS}$, an increase in the peak intensity within the Raman shift in the region of $756-765 \mathrm{~cm}^{-1}$ could also be observed. This may be related to the increase in the 
phase content of C3A. The peak within the Raman shift in the region of $756-766 \mathrm{~cm}^{-1}$ also increased when the phase fraction of $\mathrm{C} 3 \mathrm{~A}$ in the sample increased. These phenomena can also be observed in Figure 7 for the C3A-CaS samples. Additionally, the most intense peak for C3A in this study was located at approximately $766 \mathrm{~cm}^{-1}$. The comparison between the change in phase fraction for CaS and relative Raman intensity for the spectra presented in Figure 6 for C12A7-CaS and Figure 7 for $\mathrm{C} 3 \mathrm{~A}-\mathrm{CaS}$ all showed that an increase in CaS content corresponded to an increase in the Raman shift in the region of $157-162 \mathrm{~cm}^{-1}$.

For the CaS- $\mathrm{Al}_{2} \mathrm{O}_{3}$ samples, the Raman spectra shown in Figure 8 demonstrate that a change in the phase fraction of $\mathrm{Al}_{2} \mathrm{O}_{3}$ resulted in a relative Raman shift in the region of $420-425 \mathrm{~cm}^{-1}$. A similar trend in the effect of change on $\mathrm{CaS}$ for $\mathrm{CaS}-\mathrm{Al}_{2} \mathrm{O}_{3}$ can be observed in the Raman spectra shown in Figure 8 compared with Figures 4-7. Therefore, based on Figures 4-8, the Raman spectroscopy measurements made for the binary samples of MA-CaS, CA-CaS, CaS-C12A7, CaS-C3A, and $\mathrm{CaS}-\mathrm{Al}_{3} \mathrm{O}_{3}$ provided qualitative information for estimating the individual phase content for a given binary sample.

\subsection{Calibration Model for Quantitative Estimation}

The individual phases present in the binary samples system were estimated using linear calibration models to establish the relationship between the relative intensities of the Raman shift (band) and the phase fractions. The sample phase content or fraction analyzed using XRD for phase identification and XRF for elemental evaluation were used as the dependent variable for the calibration model. Furthermore, the average values of the coefficient of determination, the mean absolute error values (MAE) and the relative stabilities of the calibration variable candidates were estimated as presented in Tables 4-8. The relationship between the relative stabilities of the calibration variable and the mean absolute error values (MAE) is shown in Figures 9, 11, 13, 15 and 17. Section 2.3 provides a detailed description of how these parameters were evaluated.

Table 4. Evaluation of the coefficient of determination $\left(R^{2}\right)$ and mean absolute error (MAE) for the prediction and validation between the phase content and relative intensity of the Raman peaks and phase content for CaS-CA.

\begin{tabular}{|c|c|c|c|c|c|c|c|}
\hline \multirow[b]{2}{*}{ Phases } & \multirow[b]{2}{*}{ Relative Intensity } & \multicolumn{2}{|c|}{ Training Data } & \multicolumn{2}{|c|}{ Validation } & \multirow[b]{2}{*}{ Sum MAE } & \multirow[b]{2}{*}{ Relative Stability } \\
\hline & & Mean $\left(\mathbf{R}^{2}\right)$ & Mean (MAE) & Mean $\left(\mathbf{R}^{2}\right)$ & Mean (MAE) & & \\
\hline CaS-CA & $157 / 524$ & 0.97 & 3.49 & 0.98 & 3.71 & 7.20 & 0.48 \\
\hline CaS-CA & $157 / 790$ & 0.92 & 6.08 & 0.93 & 6.12 & 12.20 & 0.15 \\
\hline CaS-CA & $200 / 524$ & 0.94 & 5.30 & 0.94 & 5.50 & 10.80 & 0.17 \\
\hline CaS-CA & $200 / 790$ & 0.83 & 9.27 & 0.84 & 9.49 & 18.76 & 0.07 \\
\hline CaS-CA & $478 / 524$ & 0.75 & 11.72 & 0.76 & 12.12 & 23.84 & 0.05 \\
\hline CaS-CA & $478 / 790$ & 0.84 & 9.22 & 0.84 & 9.36 & 18.58 & 0.07 \\
\hline
\end{tabular}

Table 5. Evaluation of the coefficient of determination $\left(R^{2}\right)$ and mean absolute error (MAE) for the prediction and validation between the phase content and relative intensity of the Raman peaks and phase content for MA-CaS.

\begin{tabular}{|c|c|c|c|c|c|c|c|}
\hline \multirow[b]{2}{*}{ Phases } & \multirow[b]{2}{*}{ Relative Intensity } & \multicolumn{2}{|c|}{ Training Data } & \multicolumn{2}{|c|}{ Validation } & \multirow[b]{2}{*}{ Sum MAE } & \multirow[b]{2}{*}{ Relative Stability } \\
\hline & & Mean $\left(R^{2}\right)$ & Mean (MAE) & Mean $\left(R^{2}\right)$ & Mean (MAE) & & \\
\hline MA-CaS & $412 / / 157$ & 0.96 & 4.35 & 0.96 & 4.52 & 8.87 & 0.56 \\
\hline MA-CaS & $776 / 157$ & 0.72 & 11.00 & 0.72 & 11.92 & 22.92 & 0.06 \\
\hline MA-CaS & $412 / / 200$ & 0.87 & 7.53 & 0.87 & 7.84 & 15.37 & 0.14 \\
\hline MA-CaS & $412 / / 478$ & 0.76 & 11.01 & 0.77 & 11.47 & 22.48 & 0.13 \\
\hline MA-CaS & $776 / / 478$ & 0.75 & 10.65 & 0.74 & 11.29 & 21.94 & 0.07 \\
\hline MA-CaS & $776 / / 200$ & 0.63 & 12.68 & 0.62 & 13.57 & 26.26 & 0.04 \\
\hline
\end{tabular}


Table 6. Evaluation of the coefficient of determination $\left(\mathrm{R}^{2}\right)$ and mean absolute error (MAE) for the prediction and validation between the phase content and relative intensity of the Raman peaks and phase content for C12A7-CaS.

\begin{tabular}{cccccccc}
\hline & & \multicolumn{2}{c}{ Training Data } & \multicolumn{2}{c}{ Validation } & \\
\cline { 3 - 5 } Phases & Relative Intensity & Mean $\left.\mathbf{( R}^{\mathbf{2}}\right)$ & Mean $(\mathbf{M A E})$ & Mean $\left.\mathbf{( R}^{\mathbf{2}}\right)$ & Mean $($ MAE) & Sum MAE & Relative Stability \\
\hline C12A7-CaS & $517 / 157$ & 0.98 & 2.76 & 0.98 & 2.96 & 5.72 & 0.98 \\
C12A7-CaS & $517 / 200$ & 0.84 & 8.03 & 0.84 & 8.72 & 16.75 & 4.44 \\
C12A7-CaS & $781 / 157$ & 0.90 & 6.06 & 0.90 & 6.43 & 12.49 & 1.54 \\
C12A7-CaS & $781 / 200$ & 0.75 & 10.49 & 0.72 & 11.31 & 21.80 & 3.78 \\
C12A7-CaS & $774 / 157$ & 0.76 & 10.30 & 0.80 & 11.10 & 21.40 & 4.78 \\
C12A7-CaS & $774 / 200$ & 0.77 & 9.55 & 0.77 & 11.16 & 20.71 & 5.73 \\
\hline
\end{tabular}

Table 7. Evaluation of the coefficient of determination $\left(\mathrm{R}^{2}\right)$ and mean absolute error (MAE) for the prediction and validation between the phase content and relative intensity of the Raman peaks and phase content for C3A-CaS.

\begin{tabular}{|c|c|c|c|c|c|c|c|}
\hline \multirow[b]{2}{*}{ Phases } & \multirow[b]{2}{*}{ Relative Intensity } & \multicolumn{2}{|c|}{ Training Data } & \multicolumn{2}{|c|}{ Validation } & \multirow[b]{2}{*}{ Sum MAE } & \multirow[b]{2}{*}{ Relative Stability } \\
\hline & & Mean $\left(R^{2}\right)$ & Mean (MAE) & Mean $\left(\mathbf{R}^{2}\right)$ & Mean (MAE) & & \\
\hline C3A-CaS & $510 / 157$ & 0.96 & 4.03 & 0.97 & 4.07 & 8.10 & 0.67 \\
\hline C3A-CaS & $766 / 157$ & 0.88 & 6.50 & 0.88 & 6.92 & 13.42 & 0.09 \\
\hline $\mathrm{C} 3 \mathrm{~A}-\mathrm{CaS}$ & $510 / 190$ & 0.87 & 7.72 & 0.86 & 8.74 & 16.46 & 0.16 \\
\hline C3A-CaS & $766 / 190$ & 0.85 & 8.07 & 0.82 & 8.97 & 17.04 & 0.08 \\
\hline
\end{tabular}

Table 8. Evaluation of the coefficient of determination $\left(R^{2}\right)$ and mean absolute error (MAE) for the prediction and validation between the phase content and relative intensity of the Raman peaks and phase content for CaS- $\mathrm{Al}_{2} \mathrm{O}_{3}$.

\begin{tabular}{cccccccc}
\hline & & \multicolumn{2}{c}{ Training Data } & \multicolumn{2}{c}{ Validation } & \\
\cline { 3 - 6 } Phases & Relative Intensity & Mean $\left.\mathbf{( R}^{\mathbf{2}}\right)$ & Mean (MAE) & Mean $\mathbf{R}^{\mathbf{2}}$ ) & Mean (MAE) & Sum MAE & Relative Stability \\
\hline $\mathrm{CaS}-\mathrm{Al}_{2} \mathrm{O}_{3}$ & $157 / 420$ & 0.94 & 5.65 & 0.95 & 6.23 & 11.88 & 0.46 \\
$\mathrm{CaS}-\mathrm{Al}_{2} \mathrm{O}_{3}$ & $157 / 386$ & 0.58 & 14.68 & 0.59 & 15.49 & 30.17 & 0.06 \\
$\mathrm{CaS}-\mathrm{Al}_{2} \mathrm{O}_{3}$ & $157 / 760$ & 0.82 & 9.72 & 0.83 & 10.86 & 20.58 & 0.17 \\
$\mathrm{CaS}-\mathrm{Al}_{2} \mathrm{O}_{3}$ & $198 / 420$ & 0.91 & 5.49 & 0.90 & 5.84 & 11.33 & 0.14 \\
$\mathrm{CaS}-\mathrm{Al}_{2} \mathrm{O}_{3}$ & $198 / 386$ & 0.38 & 18.50 & 0.40 & 19.99 & 38.49 & 0.03 \\
$\mathrm{CaS}-\mathrm{Al}_{2} \mathrm{O}_{3}$ & $198 / 760$ & 0.80 & 9.88 & 0.82 & 11.10 & 20.98 & 0.14 \\
\hline
\end{tabular}

\subsubsection{CA-CaS Sample}

Table 4 shows the results for CA-CaS samples, where the relative intensity ratio for $\mathrm{CaS}$ at $157 \mathrm{~cm}^{-1}$ and at $524 \mathrm{~cm}^{-1}$ for CA gave the highest linear regression coefficient of determination value and the lowest mean absolute error value was better than the other peak ratios. The peak ratio of 157/524 also provided generally better relative stability estimated values, as illustrated in Figure 9. A calibration curve constructed between the relative intensity ratios of the measured phase fractions for $\mathrm{CaS}$ in the CA-CaS samples is presented in Figure 10. Therefore, based on the evaluations for CA-CaS shown in Figures 9 and 10 and Table 4, the relative intensity ratio, between $157 \mathrm{~cm}^{-1}$ for CaS and $524 \mathrm{~cm}^{-1}$ for CA, demonstrated the most suitable Raman peaks for a phase content analysis of binary CA-CaS samples. Additionally, these peaks, according to Figure 5, were the phases' most intense peaks. 


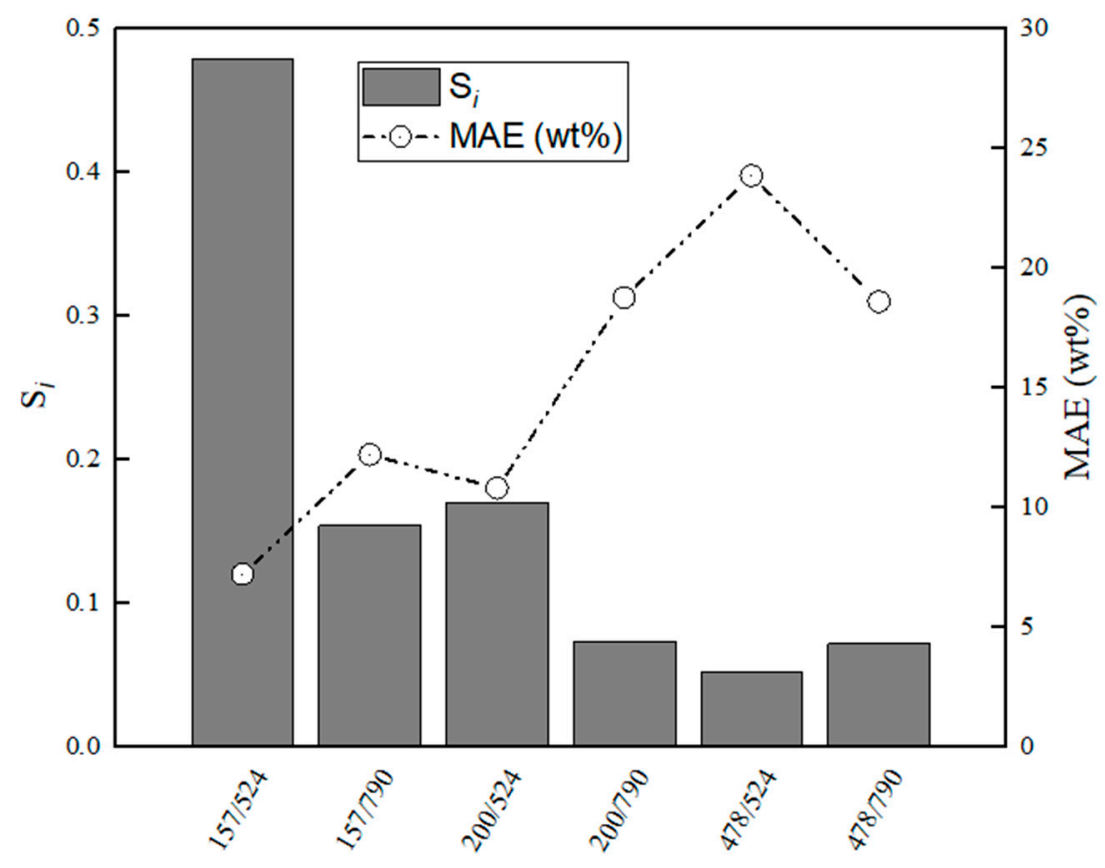

Figure 9. Evaluation of relative stabilities $(\mathrm{Si})$ of the calibration variable candidates and mean absolute error values obtained for training and validation sets for CaS-CA.

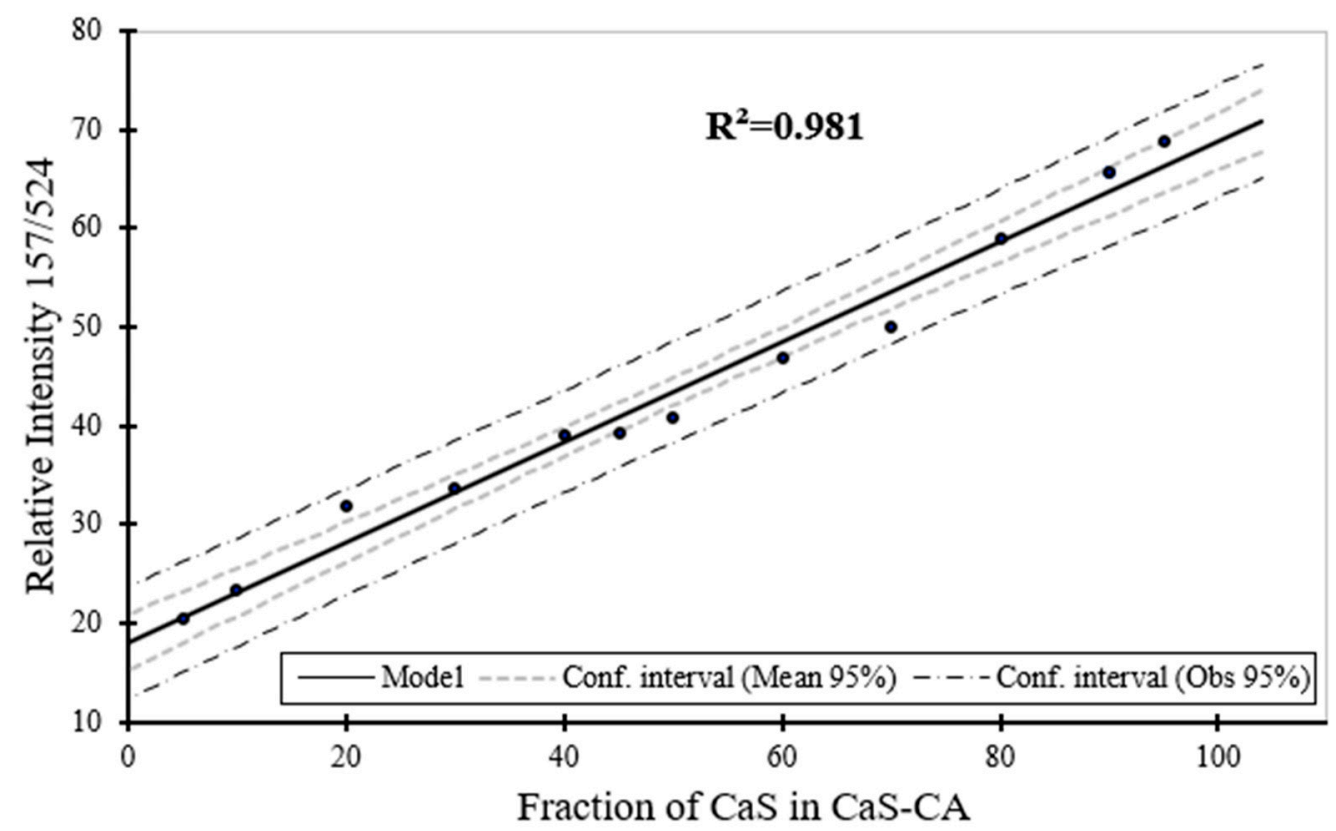

Figure 10. Raman spectroscopy estimation for the phase content (wt. \%) for CaS as a function of the phase content of CaS in CaS-CA sample.

\subsection{2. $\mathrm{MgO} \cdot \mathrm{Al}_{2} \mathrm{O}_{3}$ (MA)-CaS Samples}

Table 5 shows estimated values for the coefficient of determination and mean absolute error (MAE) relative stability for samples of MA-CaS. The ratio of the intensities for Raman shifts at $412 \mathrm{~cm}^{-1}$ for $\mathrm{MA}$, and at $157 \mathrm{~cm}^{-1}$ for CaS, showed a better coefficient of determination $\left(\mathrm{R}^{2}\right)$, and the lowest MAE value. Figure 11 also demonstrates from the relative stability analysis that a relative intensity ratio between $157 \mathrm{~cm}^{-1}$ and $412 \mathrm{~cm}^{-1}$ performed better than the other peaks used in this study. A linear regression constructed between a relative intensity of $412 / 157 \mathrm{~cm}^{-1}$ and a phase fraction for MA in the MA-CaS system is presented in Figure 12. In this study, the most intense Raman peaks at $416 \mathrm{~cm}^{-1}$ for 
MA and $157 \mathrm{~cm}^{-1}$ for CaS were the most suitable peaks for Raman spectroscopy quantitative analysis for samples containing only MA-CaS.

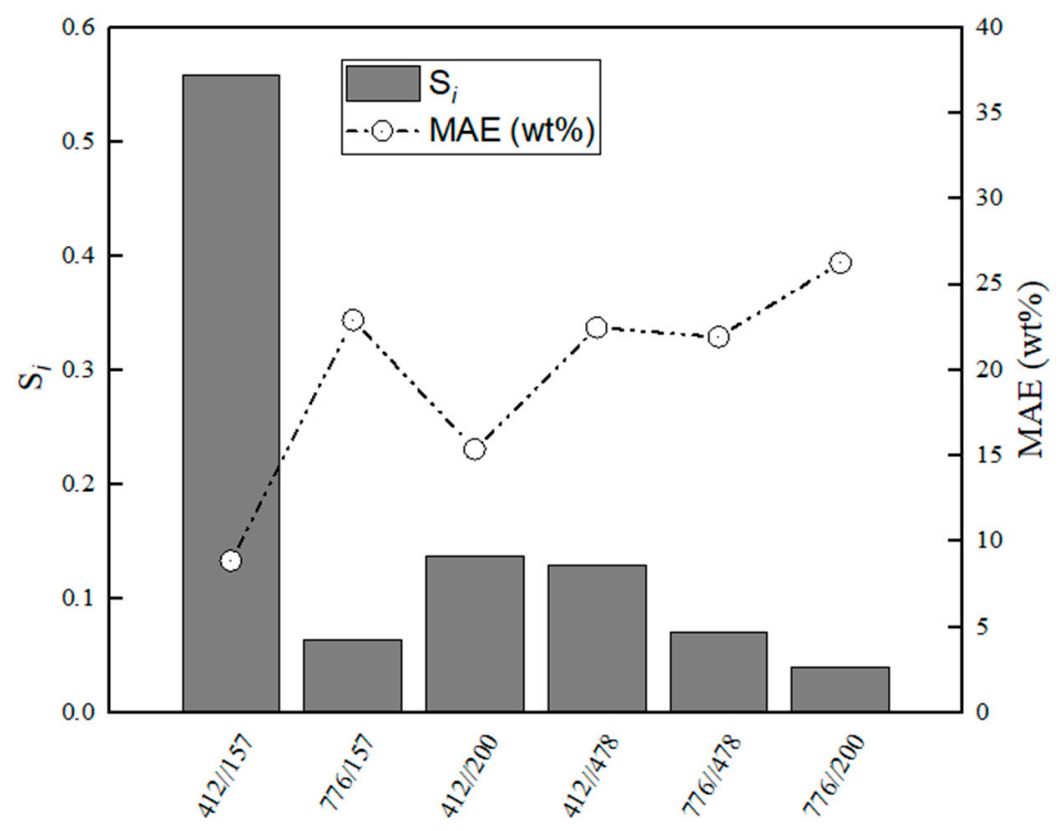

Figure 11. Evaluation of relative stabilities (Si) of the calibration variable candidates and mean absolute error values obtained for training and validation sets for MA-CaS.

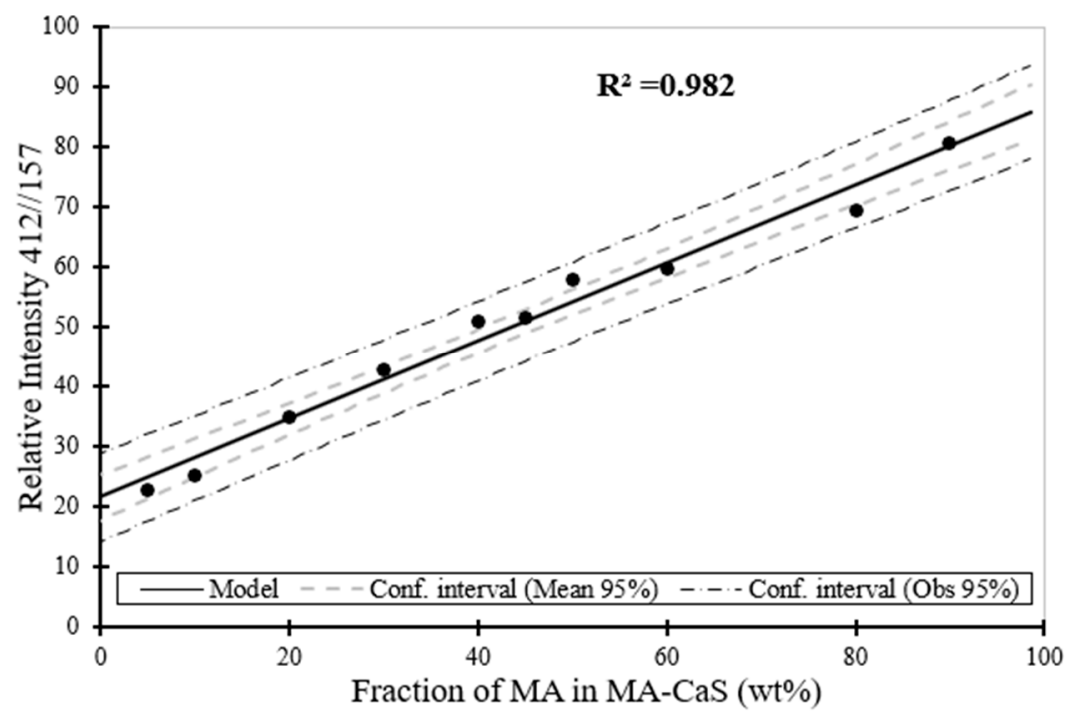

Figure 12. Raman spectroscopy estimation for the phase content (wt. \%) for MA as a function of the phase content of MA in MA-CaS sample.

\subsubsection{C12A7-CaS Samples}

According to the analysis presented in Table 6, C12A7-CaS binary samples that indicated a peak intensity ratio for the Raman peak at $517 \mathrm{~cm}^{-1}$ for $\mathrm{C} 12 \mathrm{~A} 7$ and $416 \mathrm{~cm}^{-1}$ for MA were the most suitable selection in this study, compared to the other identified peaks ratios. The coefficient of determination values and the MAE for a peak ratio of 517/157 were the best values. Additionally, the ratio of the suggested peaks (517/157) with better values in Table 6 can be observed as the most intense Raman peaks for C12A7 and CaS, as illustrated in the previous figure (Figure 6), showing the Raman spectra for C12A7-CaS samples. Furthermore, Figure 13 may explain how the stability of the Raman shift ratio $517 / 157$ performed, compared to other Raman peaks ratios. 


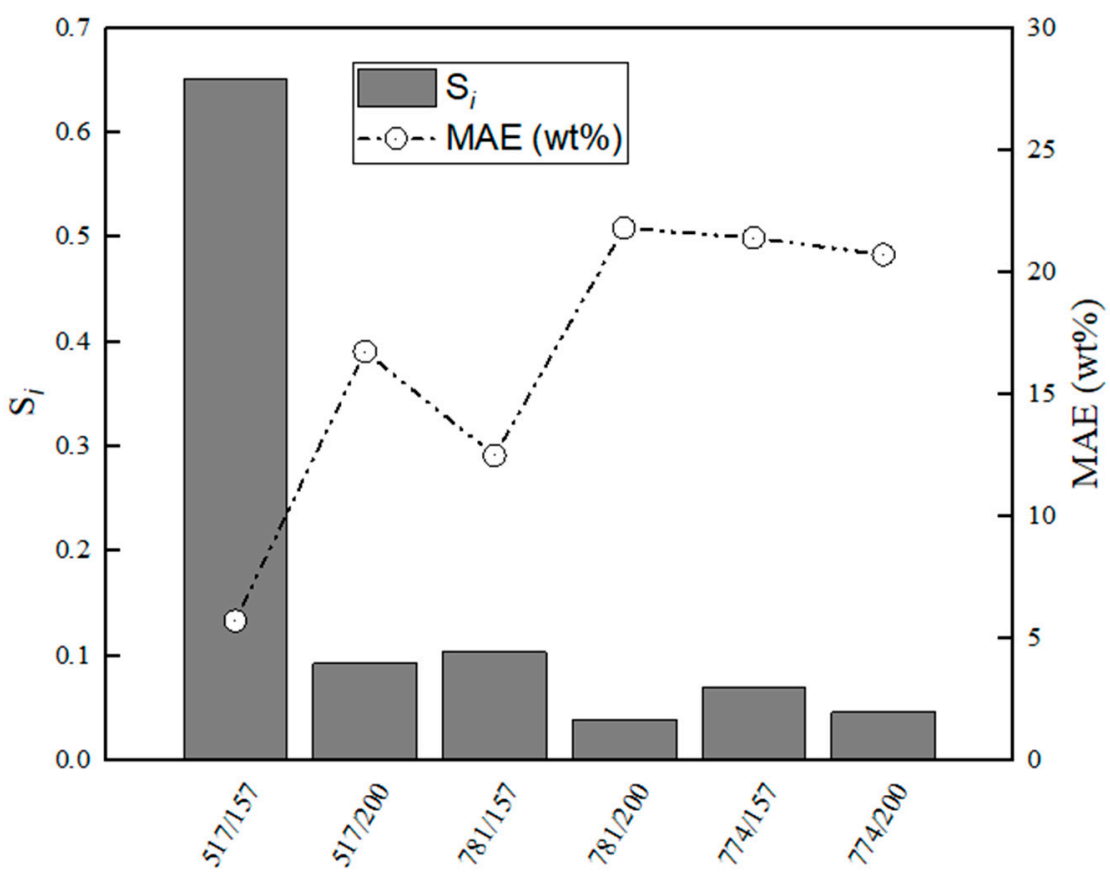

Figure 13. Evaluation of relative stabilities $(\mathrm{Si})$ of the calibration variable candidates and mean absolute error values obtained for training and validation sets for C12A7-CaS.

Therefore, using a relative intensity ratio of 517/157 for the C12A7-CaS samples provided a potential indicator for the analysis phase fraction changes in C12A7-CaS samples, based on the $\mathrm{C} 12 \mathrm{~A} 7 / \mathrm{CaS}$ ratio. Figure 14 shows a linear regression plot between the phase content for $\mathrm{C} 12 \mathrm{~A} 7 \mathrm{as}$ a function of the relative intensities of 517/157 for C12A7-CaS samples.

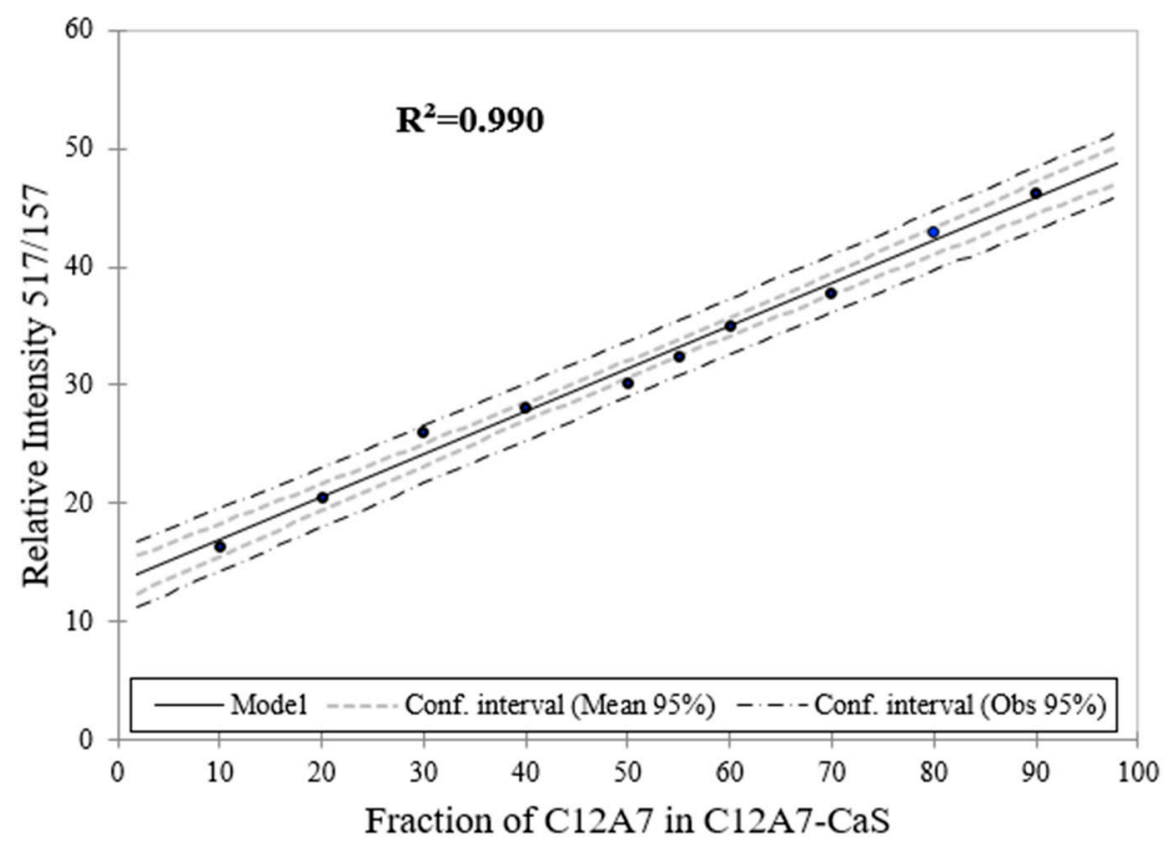

Figure 14. Raman spectroscopy estimation for the phase content (wt. \%) for C12A7 as a function of the phase content of C12A7 in C12A7-CaS sample.

\subsection{4. $\mathrm{C} 3 \mathrm{~A}-\mathrm{CaS}$ and $\mathrm{Al}_{2} \mathrm{O}_{3}-\mathrm{CaS}$}

Tables 7 and 8 provide estimated values for binary samples of $\mathrm{C} 3 \mathrm{~A}-\mathrm{CaS}$ and $\mathrm{Al}_{2} \mathrm{O}_{3}-\mathrm{CaS}$, respectively. In Table 7, the ratio of the intensities of Raman shifts at $756 \mathrm{~cm}^{-1}$ for C3A, and $416 \mathrm{~cm}^{-1}$ 
for MA, for samples of C3A-CaS had the best coefficient of determination, and better MAE values. Similarly, Table 8 shows that the intensities for a Raman shift at $157 \mathrm{~cm}^{-1}$ for CaS, and $420 \mathrm{~cm}^{-1}$ for $\mathrm{Al}_{2} \mathrm{O}_{3}$, had the best value for the coefficient of determination values, with the lowest MAE compared to the other peaks' ratios for these phases. Figures 15 and 16 also indicate that for all the Raman shift (peaks) identified for $\mathrm{CaS}, \mathrm{C} 3 \mathrm{~A}$, and $\mathrm{Al}_{2} \mathrm{O}_{3}$, the relative stability of the peak ratios for the most intense peaks performed better. Therefore, based on this study, the most intense Raman peaks ratio for $\mathrm{C} 3 \mathrm{~A}-\mathrm{CaS}$ and $\mathrm{CaS}-\mathrm{Al}_{2} \mathrm{O}_{3}$ with a Raman peak at $756 \mathrm{~cm}^{-1}$ for $\mathrm{C} 3 \mathrm{~A}, \mathrm{Al}_{2} \mathrm{O}_{3}$ at $416 \mathrm{~cm}^{-1}$, and $\mathrm{CaS}$ at $157 \mathrm{~cm}^{-1}$ was shown to be most suitable for the quantitative parameters for these samples. Figures 17 and 18 illustrate a linear regression constructed between the relative intensity and phase fraction for $\mathrm{C} 3 \mathrm{~A}$ in $\mathrm{C} 3 \mathrm{~A}-\mathrm{CaS}$ and the relative intensity and phase fraction for $\mathrm{CaS}$ in $\mathrm{CaS}-\mathrm{Al}_{2} \mathrm{O}_{3}$, respectively.

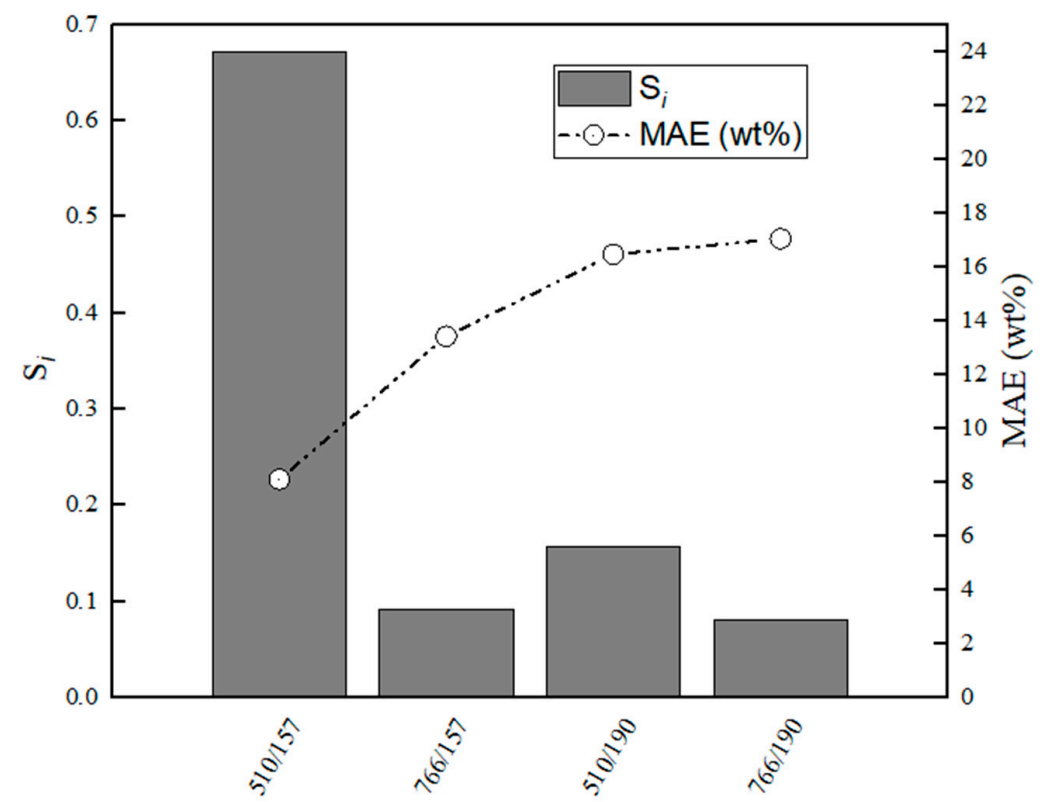

Figure 15. Evaluation of relative stabilities $(\mathrm{Si})$ of the calibration variable candidates and mean absolute error values obtained for training and validation sets for $\mathrm{C} 3 \mathrm{~A}-\mathrm{CaS}$.

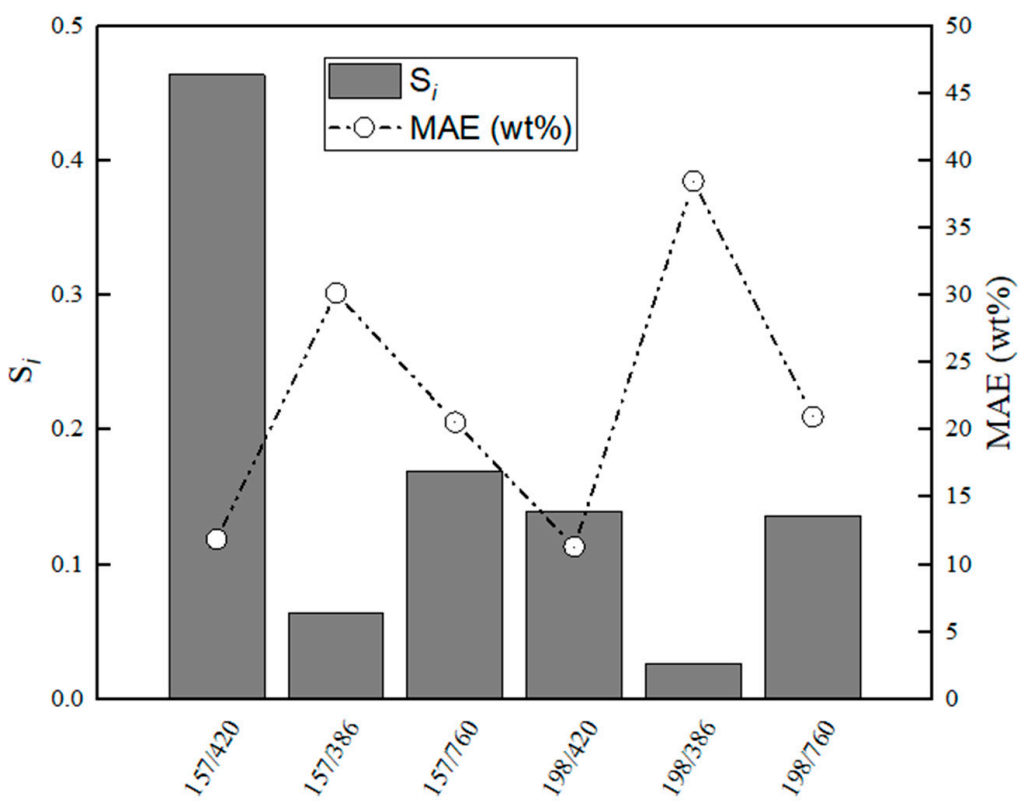

Figure 16. Evaluation of relative stabilities $(\mathrm{Si})$ of the calibration variable candidates and mean absolute error values obtained for training and validation sets for $\mathrm{CaS}-\mathrm{Al}_{2} \mathrm{O}_{3}$. 


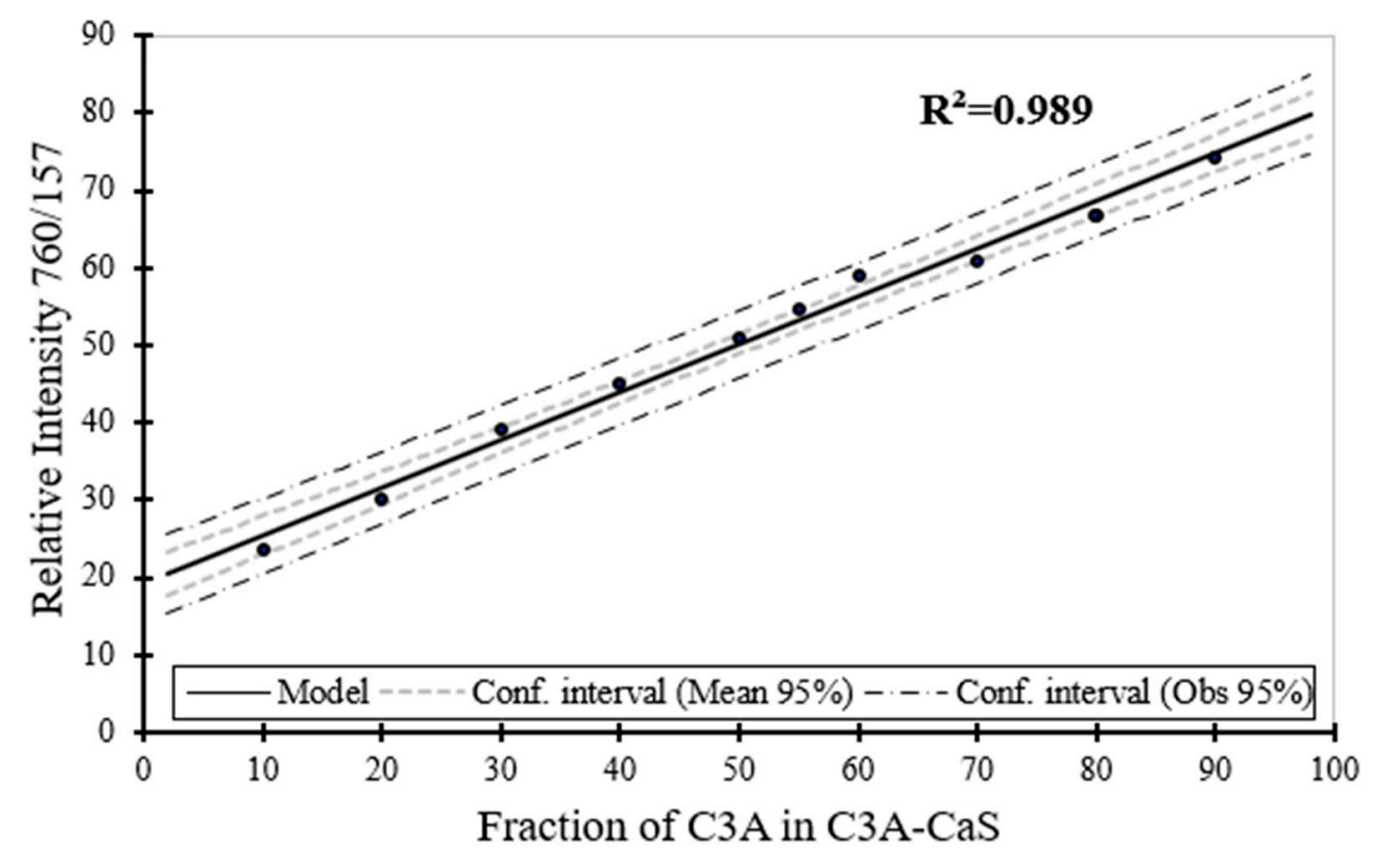

Figure 17. Raman spectroscopy estimation for the phase content (wt. \%) for MA as a function of the phase content of MA in C3A-CaS sample.

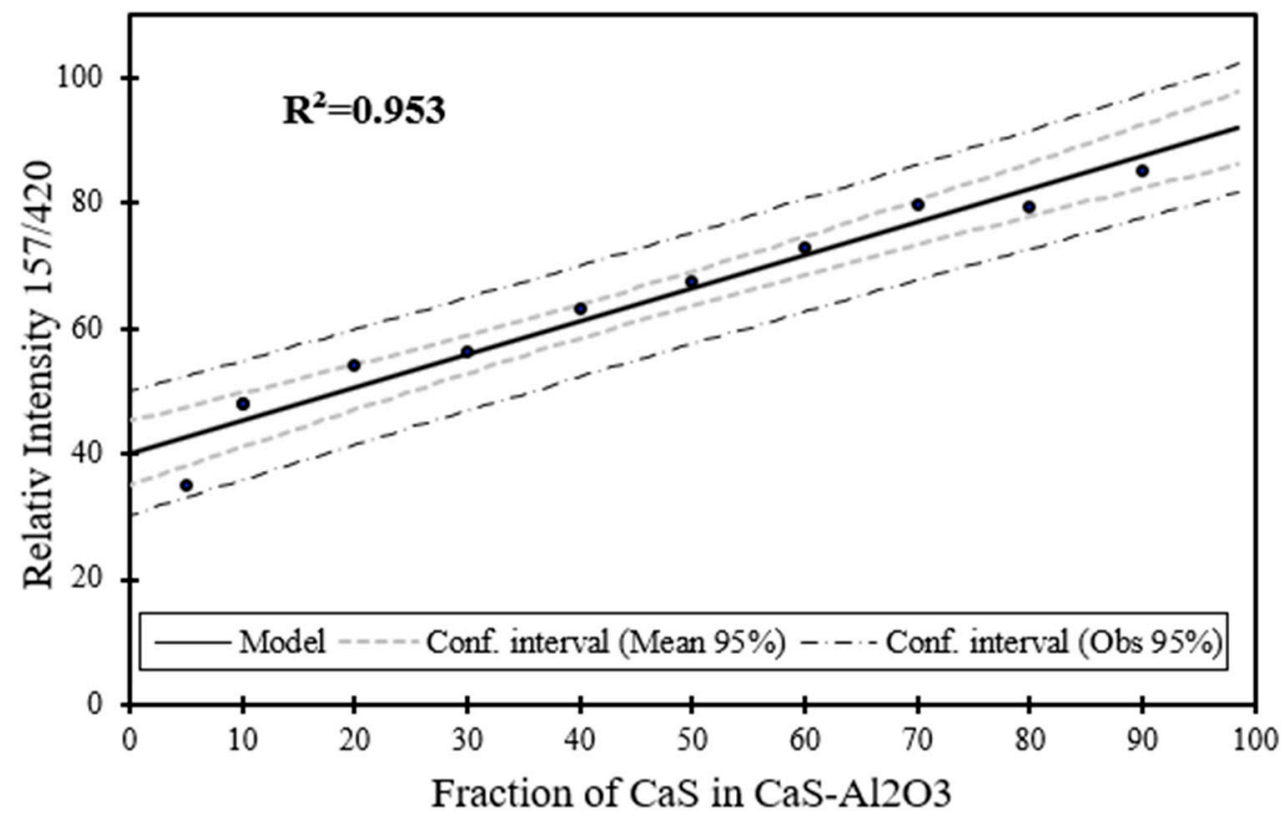

Figure 18. Raman spectroscopy estimation for the phase content (wt. \%) for MA as a function of the phase content of MA in $\mathrm{CaS}-\mathrm{Al}_{2} \mathrm{O}_{3}$ sample.

\subsection{Potential Limitations of the Study}

The use of Raman spectroscopy as a characterization technique potentially has0020some disadvantages. For example, the delay in response to the detection system and variation in incident laser power may induce measurement noise and decrease the repeatability of the measurements. In addition, the effect of fluorescence could affect the quality of the measured Raman spectra for sensitive samples. However, the samples used for this study were not fluorescence sensitive. Sample inhomogeneity could also contribute to the total error. 


\subsection{Potential Practical Applications}

Depending on the total composition of molten steel, deoxidation regime, and inclusion modification procedure, for example, via calcium treatment, duplex oxide-sulphide inclusions such as CaS-CA, $\mathrm{CaS}-\mathrm{C} 12 \mathrm{~A} 7$, and $\mathrm{CaS}-\mathrm{Al}_{2} \mathrm{O}_{3}$, can be formed in the steel melt. This study contributes to the applicability of Raman spectroscopy to non-metallic inclusion characterization with a current focus on how to quantify duplex oxide-sulphide inclusions. The most suitable Raman peak ratios for the study exhibited values for a mean absolute error (MAE) for the full data set ranging between 6.23 and $8.87 \mathrm{wt} \% \%$ and that of the coefficient of determination $\left(\mathrm{R}^{2}\right)$ between 0.94 and 0.98 for synthetic phases of $\mathrm{C} 12 \mathrm{~A} 7, \mathrm{Al}_{2} \mathrm{O}_{3}$, $\mathrm{CA}, \mathrm{C} 3 \mathrm{~A}$, and $\mathrm{MgO} \cdot \mathrm{Al}_{2} \mathrm{O}_{3}$.

This study, therefore, offers the prospect of applying Raman spectroscopy to estimate duplex oxide-sulphide, and combined with previous studies [15,16], to characterize inclusions found in steel samples, because the steel matrix is known to be Raman inactive. Additionally, the potential use of Raman spectroscopy will lead to reduced sample preparation and characterization times and can complement existing steel cleanliness analysis techniques. It is noteworthy that future studies could consider using Raman spectroscopy for a multiphase analysis consisting of three or more phases such as CaS, calcium aluminates, and spinel, because industrial steel samples can contain multiphase inclusions.

\section{Conclusions}

This study showed that Raman spectroscopy can be used as an analytical technique to estimate phase fractions for a mixture of duplex oxide-sulphide phases. The study can, therefore, be summarized as follows:

1. Raman intensity peak ratios between the values of $157 \mathrm{~cm}^{-1}$ for $\mathrm{CaS}, 412 \mathrm{~cm}^{-1}$ for $\mathrm{MgO} \cdot \mathrm{Al}_{2} \mathrm{O}_{3}$ (MA), $766 \mathrm{~cm}^{-1}$ for $\mathrm{C} 3 \mathrm{~A}, 517 \mathrm{~cm}^{-1}$ for $\mathrm{C} 12 \mathrm{~A} 7$, and $420 \mathrm{~cm}^{-1}$ for $\mathrm{Al}_{2} \mathrm{O}_{3}$ were identified as most suitable for quantifying the binary samples in this study.

2. The linear regression constructed between the relative intensity and phase fraction provided a relatively good coefficient of determination $\left(R^{2}\right)$ value, approximately averaged at $R^{2}=0.96$.

3. The calibration model error was assessed in terms of mean absolute error (MAE) with an average value of $7.22 \mathrm{wt}$. \% determined for the full data, and relatively good stability for the most intense Raman peaks for the phases for the set of the studied binary samples.

4. This study presented the prospect of using Raman spectroscopy to characterize inclusions containing CaS.

Author Contributions: Conceptualization, F.G., T.A., M.A., Q.S, and T.F.; Methodology, F.G., T.A., M.A., Q.S., T.V.; software, T.V., and F.G., validation, T.V., and F.G.; formal analysis, F.G; resources, M.H., and T.F.; writing-original draft preparation, F.G.; writing—review and editing, F.G., T.A., M.A., Q.S, T.V., and T.F.; supervision, T.F., M.H., and M.A.; project administration, M.H.; funding acquisition, M.H., and T.F. All authors have read and agreed to the published version of the manuscript.

Funding: Research is funded due I4Future doctoral program funded by the European Union's H2020 under the Marie Skłodowska-Curie grant agreement No. 713606 and the Academy of Finland Profilation Project (Academy of Finland, No. 311934).

Acknowledgments: The authors of this study wish to acknowledge the support of the I4Future doctoral program funded by the European Union's H2020 under the Marie Skłodowska-Curie grant agreement No. 713606 and the Academy of Finland Profilation Project (Academy of Finland, No. 311934).

Conflicts of Interest: The authors wish to declare no conflict of interest. 


\section{References}

1. Tervo, H.; Kaijalainen, A.; Pikkarainen, T.; Mehtonen, S.; Porter, D. Effect of impurity level and inclusions on the ductility and toughness of an ultra-high-strength steel. Mater. Sci. Eng. 2017, 697, 184-193. [CrossRef]

2. Pires, J.C.S.; Garcia, A. Modification of oxide inclusions present in aluminium-killed low carbon steel by addition of calcium. Rem Rev. Esc. Minas 2004, 57, 183-189. [CrossRef]

3. Zhang, L.; Thomas, B.G. State of the Art in Evaluation and Control of Steel Cleanliness. ISIJ Int. 2003, 43, 271-291. [CrossRef]

4. Xu, Z.Y.; Liu, J.H.; He, Z.J.; Pang, Q.H. Study on clogging mechanism of submerged entry nozzle of steel 38CrMoAl. Metalurgija 2018, 57, 79-82.

5. Sun, S.; Waterfall, S.; Strobl, N.; Liao, D.; Holdridge, D. Inclusion control with Ca treatment to improve castability of low carbon Aluminum-killed steel. In Proceedings of the 8th International Symposium on High-Temperature Metallurgical Processing, San Diego, CA, USA, 26 February-2 March 2017; p. 347.

6. Choudhary, S.K.; Ghosh, A. Thermodynamic Evaluation of Formation of Oxide-Sulfide Duplex Inclusions in Steel. ISIJ Int. 2008, 48, 1552-1559. [CrossRef]

7. Zhao, D.; Li, H.; Bao, C.; Yang, J. Inclusion evolution during modification of alumina inclusions by calcium in liquid steel and deformation during hot rolling process. ISIJ Int. 2015, 55, 2115-2124. [CrossRef]

8. Gollapalli, V.; Rao, M.B.V.; Karamched, P.S.; Borra, C.R.; Roy, G.G.; Srirangam, P. Modification of oxide inclusions in calcium-treated Al-killed high sulphur steels. Ironmak. Steelmak. 2019, 46, 663-670. [CrossRef]

9. Abdelaziz, S.; Megahed, G.; El-Mahallawi, I.; Ahmed, H. Control of Ca addition for improved cleanness of low C, Al killed steel. Ironmak. Steelmak. 2009, 36, 432-441. [CrossRef]

10. Wang, Y.; Sridhar, S.; Valdez, M. Formation of CaS on Al2O3-CaO inclusions during solidification of steels. Metall. Mater. Trans. B 2002, 33, 625-632. [CrossRef]

11. Thapa, J.; Liu, B.; Woodruff, S.D.; Chorpening, B.T.; Buric, M.P. Raman scattering in single-crystal sapphire at elevated temperatures. Appl. Opt. 2017, 56, 8598. [CrossRef]

12. Avril, C.; Malavergne, V.; Caracas, R.; Zanda, B.; Reynard, B.; Charon, E.; Bobocioiu, E.; Brunet, F.; Borensztajn, S.; Pont, S.; et al. Raman spectroscopic properties and Raman identification of CaS-MgS-MnSFeS- $\mathrm{Cr}_{2} \mathrm{FeS}_{4}$ sulfides in meteorites and reduced sulfur-rich systems. Meteor Planet Sci. 2013, 48, 1415-1426. [CrossRef]

13. Torréns-Martín, D.; Fernández-Carrasco, L.; Martínez-Ramírez, S.; Ibáñez, J.; Artús, L.; Matschei, T. Raman spectroscopy of anhydrous and hydrated calcium aluminates and sulfoaluminates. J. Am. Ceram. Soc. 2013, 96, 3589-3595. [CrossRef]

14. Dash, S.; Sahoo, R.K.; Das, A.; Bajpai, S.; Debasish, D.; Singh, S.K. Synthesis of $\mathrm{MgAl}_{2} \mathrm{O}_{4}$ spinel by thermal plasma and its synergetic structural study. J. Alloys Compd. 2017, 726, 1186-1194. [CrossRef]

15. Neuville, D.R.; Henderson, G.S.; Cormier, L.; Massiot, D. The structure of crystals, glasses, and melts along the $\mathrm{CaO}-\mathrm{Al}_{2} \mathrm{O}_{3}$ join: Results from Raman, $\mathrm{Al} \mathrm{L-} \mathrm{and} \mathrm{K-edge} \mathrm{X-ray} \mathrm{absorption,} \mathrm{and} \mathrm{27Al} \mathrm{NMR} \mathrm{spectroscopy.}$ Am. Mineral. 2010, 95, 1580-1589. [CrossRef]

16. Joo Park, H. Structure-Property Relationship of CaO-MgO-SiO 2 Slag: Quantitative Analysis of Raman Spectra. Metall. Mater. Trans. B 2013, 44, 938-947. [CrossRef]

17. Gyakwaa, F.; Aula, M.; Alatarvas, T.; Vuolio, T.; Shu, Q.; Huttula, M.; Fabritius, T. Applicability of Time-Gated Raman Spectroscopy in the Characterisation of Calcium-Aluminate Inclusions. ISIJ Int. 2019, 59, 1846-1852. [CrossRef]

18. Gyakwaa, F.; Aula, M.; Alatarvas, T.; Vuolio, T.; Shu, Q.; Huttula, M.; Fabritius, T. Characterisation of Binary Phase Mixtures of Magnesium- Aluminate Spinel and Calcium-Aluminates Using Time-Gated Raman Spectroscopy. ISIJ Int. 2020, 60, 5. [CrossRef]

19. Li, S.; Hihara, L.H. Identification of inclusions in carbon steels using micro-Raman spectroscopy. J. Raman Spectrosc. 2017, 48, 137-142. [CrossRef]

20. Feng Bai, X.; Hui Sun, Y.; Mei Chen, R.; Min Zhang, Y.; Fan Cai, Y. Formation and thermodynamics of CaS-bearing inclusions during Ca treatment in oil casting steels. Int. J. Miner. Metall. Mater. 2019, 26, 573-587.

21. Tang, H.Y.; Wang, Y.; Wu, T.; Li, J.S.; Yang, S.F. Characteristics analysis of inclusion of 60Si2Mn-Cr spring steel via experiments and thermodynamic calculations. Ironmak. Steelmak. 2017, 44, 377-388. [CrossRef]

22. Guo, J.; Cheng, S.; Cheng, Z.; Xin, L. Thermodynamics for precipitation of CaS bearing inclusion and their deformation during rolling process for Al-killed Ca-treated steel. Steel Res. Int. 2013, 84, 545-553. [CrossRef] 
23. Verma, N.; Pistorius, P.C.; Fruehan, R.J.; Potter, M.S.; Oltmann, H.G.; Pretorius, E.B. Calcium modification of spinel inclusions in aluminum-killed steel: Reaction steps. Metall. Mater. Trans. B 2012, 43, 830-840. [CrossRef]

24. Verma, N.; Pistorius, P.C.; Fruehan, R.J.; Potter, M.; Lind, M.; Story, S.R. Transient inclusion evolution during modification of alumina inclusions by calcium in liquid steel: Part II. Results and discussion. Metall. Mater. Trans. B. 2011, 42, 720-729. [CrossRef]

25. Geldenhuis, J.M.A.; Pistorius, P.C. Minimisation of calcium additions to low carbon steel grades. Ironmak. Steelmak. 2000, 27, 442-449. [CrossRef]

26. Edwards, H.G.M. Modern Raman Spectroscopy-A Practical Approach; John Wiley and Sons: Chichester, UK, 2005; p. 210.

27. Loudon, R. The Raman Effect in Crystals. Adv. Phys. 2001, 50, 813-864. [CrossRef]

28. Yellepeddi, R.; Bapst, A.; Bonvin, D. Applications of an Integrated XRF-XRD Spectrometer. J. Phys. IV Colloq. 1996, 6, 781-788. [CrossRef]

(C) 2020 by the authors. Licensee MDPI, Basel, Switzerland. This article is an open access article distributed under the terms and conditions of the Creative Commons Attribution (CC BY) license (http://creativecommons.org/licenses/by/4.0/). 